\title{
SmdA is a novel cell morphology determinant in
}

4 Ine Storaker Myrbråten ${ }^{1}$, Gro Anita Stamsås ${ }^{1}$, Helena Chan ${ }^{2,3}$, Danae Morales Angeles ${ }^{1}$, Tiril

5 Mathiesen Knutsen ${ }^{1}$, Zhian Salehian ${ }^{1}$, Volha Shapaval ${ }^{4}$, Daniel Straume ${ }^{1}$ and Morten Kjos ${ }^{1}$.

6

$7{ }^{1}$ Faculty of Chemistry, Biotechnology and Food Science, Norwegian University of Life

8 Sciences, Ås, Norway.

$9{ }^{2}$ Structural Cellular Biology Unit, Okinawa Institute of Science and Technology, Okinawa, 10 Japan.

$11{ }^{3}$ The ithree institute, University of Technology Sydney, Broadway, NSW, Australia.

$12{ }^{4}$ Faculty of Science and Technology, Norwegian University of Life Sciences, Ås, Norway. 


\section{Abstract}

14 Cell division and cell wall synthesis in staphylococci need to be precisely coordinated and controlled to allow the cell to multiply while maintaining their nearly spherical shape. The mechanisms ensuring correct placement of the division plane and synthesis of new cell wall have been studied intensively, however, hitherto unknown factors and proteins are likely to play key roles in this complex interplay. We here identified and investigated a protein with major influence on cell morphology in Staphylococcus aureus. The protein, named SmdA (for staphylococcal morphology determinant A), is a membrane-protein with septum-enriched localization. By CRISPRi knockdown and overexpression combined with different microscopy techniques, we demonstrate that proper levels of SmdA is necessary for cell division, including septum formation and cell splitting. We also identified conserved residues in SmdA that are critical for its functionality. Pulldown- and bacterial two-hybrid interaction experiments showed that SmdA interacts with several known cell division- and cell wall synthesis proteins, including penicillin binding proteins (PBPs) and EzrA. Notably, SmdA also affects susceptibility to cell wall targeting antibiotics, particularly in methicillin-resistant $S$. aureus (MRSA). Together, our results show that $S$. aureus is dependent on balanced amounts of membrane-attached SmdA in order to carry out proper cell division. 
Importance

Staphylococcus aureus is an important human and animal pathogen. Antibiotic resistance is a major problem in treatment of staphylococcal infections, and cell division and cell wall synthesis factors have previously been shown to modulate susceptibility to antibiotics in this species. In the current work we investigated the function of an essential protein named SmdA, which was identified based on its septal localization and knockdown phenotype resulting in defective cellular morphologies. We demonstrate that this protein is critical for normal cell

37 division in $S$. aureus. Depletion of SmdA sensitize resistant staphylococci to $\beta$-lactam antibiotics. This work thus reveals a new staphylococcal cell division factor and a potential

39 future target for narrow spectrum antimicrobials or compounds to resensitize antibiotic resistant staphylococcal strains. 


\section{Introduction}

Most bacteria are surrounded by a shape-determining cell envelope which protects against lysis and interacts with the extracellular milieu. The cell envelope of the opportunistic, Grampositive pathogen Staphylococcus aureus consists of a thick layer of peptidoglycan (PG) along with teichoic acids (TA) and cell wall-associated surface proteins. During a bacterial cell cycle, synthesis of PG and TA needs to be precisely regulated and coordinated with cell division, DNA replication and chromosome segregation. Tight control of these processes is critical for staphylococcal cells to maintain their integrity and nearly spherical shape as they multiply, and they are therefore attractive targets for antimicrobials (1). Exactly how such control is mediated in S. aureus is still not fully established, and hitherto unknown factors may be involved. In this work we describe a new staphylococcal cell morphology determinant.

Staphylococcal cell division is initiated by assembly of the Z-ring, consisting of polymerized FtsZ-proteins, that localizes to the future division septa (2). The Z-ring functions as a scaffold for cell division- and cell wall synthesis proteins which together constitute the divisome (3). Cell division in S. aureus occurs in alternating orthogonal planes, meaning that the new cell division plane is always perpendicular to the previous (4). Timely and spatial control of localization of the Z-ring assembly is most likely linked with chromosome segregation and DNA replication, involving proteins such as the nucleoid occlusion factor Noc, which ensures that the cells do not establish new septa across the chromosomes (5), and CcrZ, which connects initiation of DNA replication to cell division (6). The chromosomes and chromosome segregation also contribute to establish a physical barrier allowing the Z-ring only to be formed in an angle perpendicular to the previous division plane (4).

The Z-ring directs the synthesis of new PG in S. aureus to the septum. Synthesis of PG starts in the cytoplasm, where UDP-MurNAc-pentapeptide is first synthesized and then attached to the membrane by the enzyme MraY to form the PG precursor lipid I $(7,8)$. A 
GlcNAc residue and a pentaglycine side chain is attached to produce lipid II-Gly 5 (9), which is flipped to the outer leaflet of the membrane by $\operatorname{MurJ}(10,11)$ where it is incorporated into the existing PG mesh by transpeptidation (TP) and transglycosylation (TG) reactions. Specifically, the shape, elongation, division and sporulation (SEDS) proteins, FtsW and RodA with TG activity, work in pairs with monofunctional transpeptidases, the penicillin binding proteins PBP1 and PBP3, respectively $(12,13)$. While the PBP1-FtsW pair is essential and performs the septal cross wall synthesis, the non-essential PBP3-RodA pair is responsible for the slight elongation taking place in $S$. aureus. Additionally, S. aureus possesses two other PBPs; the bifunctional PBP2 with both TG and TP activity, whose role is essential in S. aureus, and the low-molecular weight PBP4, which controls the degree of PG crosslinks (14-16). Finally, MRSA strains have an additional PBP, PBP2A, a transpeptidase with low-affinity for $\beta$-lactam antibiotics $(17,18)$. In the final step of division, PG hydrolases break covalent bonds in PG for cell wall remodeling and daughter cell splitting. The major, bifunctional autolysin Atl, together with Sle1, for which expression are regulated by the two-component system WalKR, are the primary enzymes responsible for hydrolyzing the septal PG to allow splitting of daughter cells (19-22). The actual cross wall splitting is a mechanical process occurring within milliseconds $(23,24)$.

The spatiotemporal control of cell division and PG synthesis is directly and indirectly influenced by several factors. One of these is the anionic TA polymers, the second major component of the cell wall, which are either covalently linked to the PG (wall teichoic acids, WTA), or linked via a lipid-anchor to the plasma membrane (lipoteichoic acids, LTA). Mutations in enzymes involved in either WTA or LTA biosynthesis result in cells of abnormal shape and lack of septum synthesis control, probably via different mechanisms $(15,25,26)$. Furthermore, proteases, chaperones and secretion proteins, involved in production, folding and/or secretion of cell cycle proteins, may also directly or indirectly affect coordination of cell 
division and septum formation in $S$. aureus. For example, Clp-protease complexes can target both FtsZ and Sle1, and thereby have major effects on these processes (27-29).

Evidently, cell shape maintenance and control of cell division and septum formation are a complex interplay between many cellular processes where unknown key factors are yet to be discovered. We here identified a hitherto novel protein named SmdA (for staphylococcal

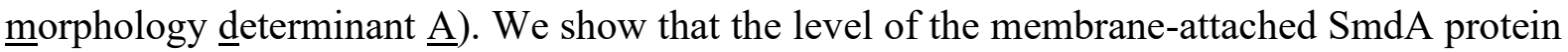
is critical for maintaining normal division progression and morphology in S. aureus, as silencing or overexpression of $s m d A$ resulted in defective cell division and septal cross wall synthesis, as well as increased sensitivity towards cell wall targeting antibiotics.

\section{Results}

\section{SmdA is a conserved staphylococcal membrane protein}

To identify novel proteins potentially involved in cell cycle and morphology control in $S$. aureus, we performed a combined depletion- and subcellular localization analysis of essential staphylococcal proteins with no annotated functions (30-32). From this, we identified a septumenriched protein (SAOUHSC_01908, named SmdA), whose knockdown resulted in cells of variable sizes that formed large clusters (see below). The function of SmdA in S. aureus was investigated further here.

SmdA is a protein of 302 amino acids which is fully conserved in species within the Staphylococcaceae family (Fig. S1). The $s m d A$ gene is monocistronic and located $>100$ bp away from the neighboring genes (SAOUHSC_01907; unknown function, and metK; Sadenosylmethionine synthase). The protein has a predicted N-terminal transmembrane helix and a C-terminal cytoplasmic part with partial homology to a so-called nuclease related domain (NERD) $\left(\mathrm{PF} 08375, \mathrm{E}=1.08 \cdot 10^{-5}\right)($ Fig. 1A). The domain was named based on distant similarities to endonucleases, and is found in bacterial, archaeal, as well as plant proteins (33). 
However, the functional role of NERD in bacteria has to our knowledge never been studied.

117 SmdA has been found to be essential in transposon mutagenesis studies in S. aureus $(30,32)$. rich medium at $37^{\circ} \mathrm{C}$ resulted in a reduction in growth compared to the control strain when spotted on agar plates (Fig. 1B). The growth rate in liquid medium was only slightly affected when $\mathrm{CFU}$ and $\mathrm{OD}_{600}$ was determined at different time points in the same culture during growth (Fig. S2A). By RT-PCR we verified that the expression of $s m d A$ was indeed fully knocked down by the CRISPRi system in S. aureus SH1000 (Fig. S2B). Since the SmdA ${ }^{\text {down }}$ strains were still viable, we attempted to construct deletion mutants of $s m d A$ by allelic replacement with a spectinomycin resistance cassette using the pMAD-vector (34). However, we were not able to obtain the deletion mutant in $S$. aureus SH1000. Similarly, for $S$. aureus strains NCTC8325-4, HG001 and the MRSA strain COL, SmdA down resulted in reduced growth on agar plates, with HG001 being most affected (Fig. 1B), but we were not able to obtain any deletion mutants in these strains. We therefore used the CRISPRi system in the different $S$. aureus strains to study the phenotypes of SmdA further.

\section{Depletion and overexpression of SmdA result in cells with highly aberrant cell shapes}

During the initial analysis, we observed that $\mathrm{SmdA}^{\text {down }}$ in S. aureus $\mathrm{SH} 1000$ resulted in clusters containing cells of variable sizes. The knockdown experiment was repeated, and exponentially growing cells were stained with fluorescent vancomycin (VanFL, binds to non-crosslinked stem peptides throughout the cell wall). SmdA ${ }^{\text {down }}$ indeed resulted in severe phenotypic defects SmdA ${ }^{\text {down }}$ as opposed to $1.6 \%$ for the control strain, Fig. 1D) and abnormal, non-spherical morphology (Fig. 1E). The SmdA ${ }^{\text {down }}$ cells were also significantly larger than the control strain (Fig. 1F). 
(Fig. 2A). In addition to lysis, cells with several non-perpendicular- or parallel septa were frequently observed, resulting in cells, or small cell clusters, with aberrant morphologies (Fig. observed for the NCTC8325-4, HG001 and COL strains, with the HG001 strain being more affected by SmdA down than the other two (Fig. S3 and Fig. S4).

Since reduced levels of SmdA led to defects in cell division and morphology of $S$. aureus, we next wondered whether overexpression of SmdA would affect the cells. An ectopic

S5A). Although less evident than for $\mathrm{SmdA}^{\text {down }}$, overexpression of SmdA also resulted in clusters of cells with several septa per cell as defined by VanFL staining (Fig. S5A) $(3.9 \%$, n $=181$ for SmdA overexpression, compared to $20.1 \%$ for SmdA ${ }^{\text {down }}$, and $1.6 \%$ for the control).

Together, these knockdown- and overexpression experiments clearly demonstrate that septum formation and splitting in S. aureus are dependent on proper levels of SmdA.

\section{Depletion of SmdA results in increased sensitivity towards antimicrobials targeting cell}

\section{wall synthesis}

Given the negative effect SmdA depletion had on cell morphology and -division, we reasoned that reduced expression of SmdA could influence the sensitivity of $S$. aureus to cell wall targeting antibiotics. To test this, SmdA ${ }^{\text {down }}$ strains were treated with PBP-targeting $\beta$-lactams 
wall synthesis by targeting the terminal D-Ala-D-Ala on the stem peptides of nascent PG (36)), tunicamycin (targeting TarO and MraY, enzymes involved in the early stages of WTA and PG synthesis, respectively (37)), targocil (targeting the WTA exporter TarG (38)) and Congo Red (inhibitor of the LTA biosynthesis enzyme LtaS (39)) (Table 1). Two antibiotics with alternative targets; tetracycline (targeting protein synthesis) and ciprofloxacin (a quinolone targeting DNA synthesis), were also included.

For the methicillin-susceptible S. aureus (MSSA) strain SH1000, a two-fold reduction in minimum inhibitory concentration (MIC), compared to the control, was observed for oxacillin and cefoxitin in SmdA ${ }^{\text {down }}$. More notably, in the MRSA strain COL, SmdA ${ }^{\text {down }}$ sensitized the COL strain towards all $\beta$-lactams with a 2- to 8-fold reduction in MIC compared to the control (Table 1). SmdA depletion did not seem to significantly influence vancomycin susceptibility. Strikingly, however, we observed that $\mathrm{SmdA}^{\text {down }}$ cells became highly sensitive towards tunicamycin, with a 64-fold reduction in MIC compared to the control for S. aureus SH1000 and $>4$-fold reduction for COL $(40,41)$. We therefore also tested the tunicamycin sensitivity of the NCTC8325-4 and HG001 SmdA ${ }^{\text {down }}$ strains, which also showed increased susceptibility towards tunicamycin (HG001; 125-fold reduced MIC and NCTC8325-4; 4-fold reduced). While no difference in MIC was observed for targocil, the SmdA down strains also displayed increased sensitivity towards Congo Red. Finally, SmdA depletion in S. aureus SH1000 led to a 2- to 4-fold reduction in MIC against tetracycline, compared to the control, however, depletion of SmdA in COL did not change its sensitivity towards tetracycline or ciprofloxacin (Table 1).

\section{SmdA has no major effects on the TA biosynthetic pathways}

The increased sensitivity to tunicamycin and Congo Red in SmdA ${ }^{\text {down }}$ strains, prompted us to study whether there were any major alterations in the TA in these cells, although it was also 
noted that no changes in sensitivity was observed for the WTA export inhibitor targocil (Table 1). Notably, the SmdA ${ }^{\text {down }}$ strain displayed morphologies reminiscent of what has previously been reported for cells depleted of TA, i.e., with larger cell sizes, cells with irregular septum formations and reduced splitting $(26,37,38,42)$. It has previously been shown that there is a synthetic lethal relationship between the WTA and LTA biosynthetic pathways $(42,43)$, and it could therefore be hypothesized that hypersensitivity to tunicamycin could result from deficient LTA biosynthesis in the $s m d A^{d o w n}$ mutants, Using an anti-LTA antibody, we compared the quantity and lengths of LTA in the SmdA ${ }^{\text {down }}$ - and control strains for SH1000, NCTC8325-4, HG001 and COL (Fig. S6A). For HG001, the strain with most severe division defects, we observed a reduction in LTA amounts in $\mathrm{SmdA}^{\text {down }}$ and this can possibly contribute to the severe phenotype of this strain. However, no consistent changes in LTA amounts or lengths were observed between the SmdA depletions and the controls in the four strains. Furthermore, we could not detect any LTA release into the growth medium in the depletion strains, indicating that the stability of LTA (44) was intact (Fig. S6B). We therefore conclude that SmdA does not have any consistent effect on LTA synthesis across strains.

WTA has been shown to protect cells from the LTA-inhibitor Congo Red. Without WTA, cells became hypersensitive towards Congo Red (MIC of $<4 \mu \mathrm{g} / \mathrm{ml}$ for $\operatorname{tar} O$ deletion mutants and $>1024 \mu \mathrm{g} / \mathrm{ml}$ for wild-type cells) (45). Although to a much lesser degree, SmdA depletion strains were also more sensitive to Congo Red compared to the controls (Table 1), and we therefore looked into whether WTA could be disturbed in a SmdA ${ }^{\text {down }}$ strain. Cells without WTA has previously been shown to lack the dark, electron-dense layer observed in TEM images of crosswalls of $S$. aureus wild type cells (Fig. S6C) $(37,46)$. TEM images of $\mathrm{TarO}^{\text {down }}$ and $\mathrm{SmdA}^{\text {down }}$ showed that $\mathrm{TarO}^{\text {down }}$, as expected $(37,46)$, lacked this dark, highdensity layer, while it was still present in the SmdA ${ }^{\text {down }}$ strain, suggesting that WTA was still produced (Fig. S6C). We also performed Fourier transform infrared spectroscopy (FTIR), 
which has been used before to detect differences in the composition of WTA due to variable glycosylation patterns $(44,47)$. As expected, changes in the FTIR spectra were evident in the polysaccharide region $\left(1200 \mathrm{~cm}^{-1}-800 \mathrm{~cm}^{-1}\right)$ for the $\mathrm{TarO}^{\text {down }}$ strain compared to the control, with the most significant differences recorded for the peaks at $1076 \mathrm{~cm}^{-1}, 1048 \mathrm{~cm}^{-1}, 1033 \mathrm{~cm}^{-}$ ${ }^{1}$ and $1000-970 \mathrm{~cm}^{-1}$, representing $\alpha$ - and $\beta$-glycosidic bonds in WTA (47). However, no changes were observed between SmdA ${ }^{\text {down }}$ and the control (Fig. S6D). Together, these results suggests that SmdA has no major effect on the WTA biosynthetic pathway.

\section{SmdA is important in several stages of staphylococcal cell division}

To identify potential protein interaction partners of SmdA, we next performed a protein pulldown experiment using GFP-trapping with a chromosomal $s m d A-m(s f) g f p$ fusion strain. Interestingly, the major staphylococcal autolysin Atl, as well as the bifunctional PBP2 were identified, along with 12 other proteins (Table S1). The experiment was repeated in a strain with plasmid-based expression of SmdA-m(sf)GFP, and this setup resulted in an extended list of proteins that were pulled down, probably due to the elevated expression of SmdA-m(sf)GFP. Selecting the proteins for which at least 10 unique peptides were detected and with a fold change of $>2$ compared to the control, resulted in a list of 57 proteins (Table S1). Several proteins with activity involved in protein folding, secretion and/or degradation (e.g., FtsH, PrsA, SpsB, ClpB, ClpC, SecD) were identified in this assay, in addition to the penicillinbinding proteins PBP1, PBP2, PBP3 and the early division protein EzrA. All the 14 proteins identified in the initial experiment were also pulled down in the second experiment.

Bacterial two-hybrid analyses of the SmdA-PBP1-3 and SmdA-EzrA were performed to see whether these interactions could be reproduced in a heterologous system. The proteins were fused either $\mathrm{N}$ - or $\mathrm{C}$-terminally to the domains of adenylate cyclase, an enzyme which catalyzes the production of cyclic adenosine monophosphate (cAMP) and eventually induction 
of $\beta$-galactosidase production when brought in proximity by interaction between the target proteins. Indeed, SmdA interacted with PBP2, as well as PBP1, PBP3 and EzrA in the twohybrid assays (Fig. 3A). By expressing a version of SmdA without its N-terminal membrane domain $(\operatorname{SmdA} \triangle \mathrm{TMH})$, we also show that the observed interactions between SmdA and the PBPs in this assay occur via the transmembrane segment, while the interaction with EzrA was retained for SmdA $\triangle \mathrm{TMH}$. The latter suggests that EzrA interacts with the intracellular part of SmdA (Fig. 1A). Furthermore, we also show that SmdA is able to self-interact, and also this interaction is dependent on the transmembrane helix (Fig. S7). somehow important for proper regulation and/or localization of PBPs in S. aureus (Fig. 1 and

Fig. 2). The VanFL approach used above (Fig. 1C) labels non-crosslinked PG throughout the cell surface. Therefore, to determine more precisely the sites of active PG synthesis in S. aureus NCTC8325-4 SmdA down and SmdA overexpression cells, we pulse-labelled the cells for $90 \mathrm{sec}$ with the fluorescent D-amino acid 7-hydroxycoumarincarbonylamino-D-alanine (HADA), a molecule which is integrated into PG by the specific activity of transpeptidases (48). In the control cells, the expected midcell-localized band was observed (Fig. 3B). However, in the SmdA down strain, we observed a more diffuse HADA signal with PG synthesis often occurring at several sites within the cell, forming patterns visible as crosses or Y-shapes (Fig. 3C). Similar observations were made in the cells overexpressing SmdA, although with a lower frequency (Fig. 3D-E). Thus, the site of active transpeptidation (and thus probably at least one of the PBPs) is mis-localized when the levels of SmdA is altered. knocking down $s m d A$ in a strain expressing a chromosomal ezrA-gfp fusion (Fig. 3F). Indeed, abnormal localization patterns for EzrA-GFP was observed with similar frequency as the abnormal HADA labelling (Fig. 3G). These results thus suggest that depletion of SmdA, 
directly or indirectly, influences the localization of both early and late divisome proteins in $S$.

aureus.

Furthermore, the major autolysin Atl was also pulled down with SmdA. Atl is a secreted multidomain enzyme, which is processed to an acetylmuramyl-L-alanine amidase and $\beta$-Nacetylglucosaminidase, involved in septal cross wall splitting resulting in daughter cell separation (19). SmdA down cells frequently displayed increased clustering (Fig. 2, Fig. S4). This indicates reduced cross wall splitting, a phenotype also observed in $\Delta a t l$ mutants and WalKR depleted cells $(22,49)$. WalKR is the two-component regulatory system controlling the expression of atl and other cell wall hydrolase encoding genes (22). To assess the reduced cross wall splitting phenotype in more detail, we performed Triton X-100-induced autolysis assays on the cultures. Indeed, reduced autolysis was observed in $\mathrm{SmdA}^{\text {down }}$ cells, demonstrating reduced autolytic activity (Fig. 4A). The lysostaphin sensitivity was also reduced (Fig. 4B), suggesting alterations in the cell wall affecting the lytic properties of this enzyme. It should be noted that the resistance towards Triton X-100- and lysostaphin-induced autolysis in the SmdA ${ }^{\text {down }}$ strain was clearly less compared to the control strain where walR, and thus all the regulated autolysins, was knocked down. It should also be noted that Triton-X induced autolysis was not severely altered upon overexpression of SmdA (Fig. S5B).

\section{SmdA localizes at the septal region after FtsZ}

The SmdA-m(sf)GFP fusion protein displayed a septum-enriched signal when expressed ectopically from the low copy-number plasmid pLOW (Fig. 5A). In order to analyze the SmdA localization with native expression levels, a chromosomally integrated version of smdA$m(s f) g f p$ was made, in which SmdA was expressed with m(sf)GFP fused to its C-terminus. Localization analyses in these cells further confirmed the septum-enriched localization of the fusion protein (Fig. 5A), with an average septum/periphery fluorescence signal ratio of 3.4 (n 
$=52$, see Materials and Methods). To visualize the localization of SmdA relative to the cell growth, suggesting that the cells did not tolerate such double-labelling. Instead, we therefore created a double-labelled strain in which SmdA-mYFP and FtsZ-mKate2 were co-expressed from plasmids, while the native $s m d A$ and $f t s Z$ genes were still present on the chromosome. around in the membrane when the Z-ring is formed (Fig. 5B), and that a septum-enriched localization occurs as the septal cross wall is being synthesized. This was further confirmed by stimulated emission depletion (STED) microscopy analysis (Fig. 5C). STED imaging also revealed that there was no apparent co-localization of SmdA-mYFP and FtsZ-mKate2 in newborn cells before FtsZ-constriction initiates. Combined, the localization of SmdA is reminiscent of the localization of PBPs in S. aureus (11), but appears to localize to the septal area after the early divisome proteins such as $\operatorname{EzrA}(50,51)$.

The SmdA protein is anchored to the membrane by a single transmembrane helix (Fig.

1A). To verify its significance for the septal localization, we ectopically expressed a version of SmdA without the transmembrane helix $(\operatorname{SmdA} \Delta \mathrm{TMH})$. The N-terminally truncated SmdA $\triangle$ TMH-m(sf)GFP localized to the cytoplasm of the cells (Fig. 5A). This shows that while the transmembrane helix is critical for protein-protein interactions and subcellular localization of SmdA, the interaction observed between EzrA and SmdA $\Delta \mathrm{TMH}$ (and full-length SmdA) (Fig. 3A) is probably not involved in determining the localization of this protein. During these latter experiments, we noticed that SmdA $\Delta \mathrm{TMH}-\mathrm{m}(\mathrm{sf}) \mathrm{GFP}$ overexpression led to cells with obvious morphology defects. In fact, overexpression of SmdA $\triangle \mathrm{TMH}$ (without the GFP-tag) (Fig. 6A) strikingly resulted in a more extreme phenotype than overexpression of full length SmdA (Fig. 3D, Fig. S5). The cells were often inflated or 
with a bean-shaped appearance (Fig. 6A). HADA pulse labelling of these cells revealed a

highly abnormal PG incorporation pattern, with the fluorescent signal forming both condensed demonstrates that membrane attachment is critical for the localization and function of SmdA.

Conserved amino acids in the predicted NERD domain are critical for the function of

\section{SmdA}

The functional importance of the NERD domain (Fig. 1A) has, to our knowledge, neither been studied nor verified previously in any bacterial protein. As mentioned, we observed that overexpression of SmdA $\triangle \mathrm{TMH}$ led to severe phenotypic changes in the staphylococcal morphology (Fig. 6A). We decided to use this as a tool to gain insight into whether the predicted NERD domain is important for the function of SmdA. Multiple sequence alignment of SmdA proteins from different staphylococcal species (Fig. S1) revealed conserved residues in this domain, and site directed mutagenesis was used to create two versions of SmdA $\Delta \mathrm{TMH}$ containing mutations in the NERD domain: one in which H145 was changed to Ala (mut1), and a second containing the mutations R150A and T151A (mut2). Furthermore, we also observed from the alignment that the C-terminus of SmdA is highly conserved (Fig. S1), and another C-terminally mutated variant was created (mut3; F280A, H281A). The threedimensional structure of SmdA, predicted by AlphaFold (52), suggests that the N-terminal part of the protein folds into a long $\alpha$-helix and that the NERD domain is located within the Cterminal structured part of the protein (Fig. $6 \mathrm{C}$-II). The mutated SmdA $\Delta \mathrm{TMH}$ versions were overexpressed in a wild-type background. Expression of these mutated variants indeed partially, or fully, abolished the phenotypic defects observed when overexpressing the nonmutated SmdA $\triangle \mathrm{TMH}$ version. HADA staining of mut1 (H145A) showed septum placement and PG synthesis comparable to wild-type cells, while mut2 (R150A, T151A) and mut3 

abolished when the mutated variants were expressed under the same conditions. This strongly suggests that the given residues in both the predicted NERD and the conserved C-terminus are important for the function of SmdA.

\section{Discussion}

The results presented here provide the first functional insights into the conserved staphylococcal protein SAOUHSC_01908, here named SmdA. SmdA, a protein conserved within the Staphylococcaceae family, is critical for maintaining cell morphology and for proper progression of cell division in different $S$. aureus strains (including MRSA and MSSA). Unbalanced levels, as well as loss of proper subcellular localization, of SmdA, result in severe cell morphology defects due to mis-localized cell division, uncontrolled cell wall synthesis, and lack of proper cross wall splitting.

We observed that knockdown of SmdA increased the sensitivity of S. aureus to several cell wall targeting antibiotics, including $\beta$-lactams and tunicamycin (Table 1). Many of the frequently used antibiotics, including $\beta$-lactams, target cell wall synthesis, but the rise of both methicillin- resistant- and vancomycin-resistant $S$. aureus (MRSA and VRSA) have made $S$. aureus infections more difficult to treat and novel anti-staphylococcal targets and strategies are needed. Targeting cell cycle proteins have been shown to re-sensitize resistant staphylococci towards existing antibiotics due to synergistic effects (53-55). For example, inactivation of some proteins involved in WTA synthesis sensitizes MRSA to $\beta$-lactams $(37,56)$. The same is also the case for a diversity of factors contributing to cell division and cell wall biogenesis, including FtsZ, FtsA, PBP4 and most proteins involved in the PG synthesis pathway (55). The 
linked to $\beta$-lactam sensitivity $(57,58)$, and recently, inactivation of the autolytic cell wall amidase Sle1 (21), or the membrane proteins AuxA and AuxB (44), were shown to result in increased sensitivity to $\beta$-lactams. Mechanisms of re-sensitization in these cases vary and may be a result of weakened cell wall, as well as inactivation or mis-localization of PG synthesis, including the key resistance determinant PBP2A. The large number of factors affecting $\beta$ lactam sensitivity reflects the tight links between different processes involved in cell wall biosynthesis, and most likely SmdA affects several steps in the cell division process (Fig. 1-3). The exact mechanism by which SmdA affects these processes remains to be determined. Our results suggest that cell division and PG synthesis, but not teichoic acid biosynthesis, is affected. This is supported by observations showing mis-localization of cell division and PG synthesis in SmdA ${ }^{\text {down }}$ cells (Fig. 1-3). Furthermore, SmdA down cells displayed hypersensitivity towards tunicamycin (targeting enzymes involved both in PG and WTA synthesis), but not towards targocil (targeting the WTA exporter only) (38). Possibly, SmdA influences the localization of cell division and cell wall synthesis by direct protein-protein interactions. This is supported by the SmdA-EzrA and SmdA-PBP1-3 interactions, combined with the abnormal localization of EzrA-GFP and HADA incorporation in SmdA ${ }^{\text {down }}$ cells (Fig. 3). In fact, the division defects observed in $\mathrm{SmdA}^{\text {down }}$ cells (Fig. 1-3) are reminiscent of previous studies of ezrA null mutants, strains with point mutations in FtsZ or cells exposed to Z-ring inhibitors (50, $51,59,60)$. However, the contribution of the identified interactions to the observed phenotypes must be investigated further, particularly since the subcellular localization of SmdA-m(sf)GFP does not appear to overlap with the Z-ring throughout the cell cycle. The SmdA-localization, which depends on the transmembrane helix, is instead more similar to the reported localization of PBPs (Fig. 5) (11, 50, 51).

Lack of cross wall splitting is another prominent feature of the SmdA depleted cells

(Fig. 2 and 4). After septum formation, cells remain attached, forming clusters of mis-shaped 
cells. Indeed, the autolytic activity was reduced in the SmdA ${ }^{\text {down }}$ cells (Fig. 4). The major autolysin Atl was also pulled down together with SmdA-m(sf)GFP as one of the major hits (Table S1). Atl is an extracellular processed protein whose amidase and glucosaminidase domains together process $\mathrm{PG}$ in the septum to allow splitting. It is possible that SmdA somehow influences the export or processing of Atl. In this context, it is interesting to note that proteases, foldases and chaperones (FtsH, PrsA, SpsB, ClpC, ClpB, HtrA1) were also pulled down with SmdA (Table S1). It remains to be determined whether these interactions have any functional relevance, however, perturbation of such pathways may have major consequences for cell division and septal placement as they are important for proper folding and secretion of key proteins involved in such processes. This has, for example, previously been demonstrated for the chaperone $\mathrm{ClpX}$, which is critical for coordination of autolysins and cell division proteins (29). Involvement in such a mechanism could also explain the pleiotropic phenotypes observed in SmdA ${ }^{\text {down }}$ cells, affecting several stages in the cell division process.

A part of SmdA displays limited similarity to the so-called nuclease related domain (NERD). This domain, which is found in a broad range of bacterial species and in some archaea and plants, was initially identified on a virulence-plasmid from Bacillus anthracis (33), and has later been suggested to belong to a superfamily of phosphodiesterases (61). The majority of NERD proteins are single-domain proteins, but they are also occasionally found together with a kinase-, pseudokinase- or helicase domain (62). The actual function of the NERD has, to our knowledge, however, not been studied experimentally. The results in this paper show that conserved residues in the predicted NERD are important for the functionality of SmdA, thus demonstrating for the first time a functional role of this domain (Fig. 6). Although highly speculative at this point, it would be interesting if a cell division factor such as SmdA had DNA-interacting capabilities and thus forming a potential link between the membraneassociated cell division proteins and the nucleoid. It should also be noted that several of the 
most conserved residues of the NERD domain (33) are not found in SmdA, suggesting a

417 functional diversity among proteins harboring homology to this domain and implying that the NERD of SmdA may have functions unrelated to the nucleoid.

It is also interesting to note that the effect of SmdA knockdown was different between

strains. For example, SmdA ${ }^{\text {down }}$ resulted in a more severe phenotype in HG001 compared to

NCTC8325-4 and SH1000 (Fig. 1, Fig. S3-S4), although these strains derive from the same parent (63). While HG001 contains prophages, NCTC8325-4 and SH1000 have been cured of these, and it could for example be speculated that the stress imposed by knockdown of SmdA somehow results in prophage induction in HG001 and thereby a more severe phenotype. Understanding of these and other strain differences could also help to further pinpoint the exact function of SmdA.

The staphylococcal genome encodes hundreds of essential proteins, which all represent potential target sites for antimicrobials. To be able to fully exploit the antibiotic target repertoire, it is critical to understand how essential proteins are involved and linked between different cell cycle processes. In this work, we identified and characterized SmdA as a novel factor essential for cell morphology and cell division in $S$. aureus. Based on the results presented here, future research should aim at pinpointing the molecular mechanism by which in increased sensitivity to $\beta$-lactams, it may as such also be a possible future target for combatting $\beta$-lactam resistance by re-sensitizing MRSA to these antibiotics.

\section{Materials and Methods}

\section{Bacterial strains, growth conditions and transformations}

439 Escherichia coli IM08B (64), E. coli XL1-Blue and E. coli BTH101 were grown in lysogeny broth (LB) at $30-37^{\circ} \mathrm{C}$ with shaking or on lysogeny agar (LA) plates at $30-37^{\circ} \mathrm{C}$, with 100 
$\mu \mathrm{g} / \mathrm{ml}$ ampicillin and/or $50 \mu \mathrm{g} / \mathrm{ml}$ kanamycin for selection. S. aureus SH1000, NCTC8325-4,

$37^{\circ} \mathrm{C}$ with shaking or on BHI/TSA plates at $37^{\circ} \mathrm{C}$. For selection, $10 \mu \mathrm{g} / \mathrm{ml}$ of chloramphenicol,

$5 \mu \mathrm{g} / \mathrm{ml}$ of erythromycin, $15 \mu \mathrm{g} / \mathrm{ml}$ neomycin or $100 \mu \mathrm{g} / \mathrm{ml}$ spectinomycin were added. For induction of gene expression, 50 or $300 \mu \mathrm{M}$ isopropyl $\beta$-D-1-thiogalactopyranoside (IPTG) or $2.5 \mathrm{ng} / \mathrm{ml}$ anhydrotetracycline (ATc) were added to the bacterial cultures. electrocompetent $S$. aureus cells and electroporation were performed according to Löfblom et al (65). Bacterial strains used in this study are listed in Table S2.

\section{Genetic modifications}

For all cloning, DNA fragments were amplified from S. aureus SH1000 genomic DNA, and cloning was performed with restriction digestion (New England Biolabs [NEB]) and subsequent ligation using T4 DNA Ligase (NEB), unless otherwise stated. Ligation mixtures were transformed into E. coli IM08B, and sequence-verified plasmids were transformed into S. aureus. All strains and primers used in this study are listed in Table S2 and Table S3, respectively.

\section{Fluorescent fusion constructs}

Construction of $p L O W$-smdA-m(sf)gfp. Monomeric superfolder GFP, $m(s f) g f p$, was initially using forward primer im1_linker_FP_F_BamHI (annealing to the linker sequence) and reverse

464 primer im2_m(sf)gfp_R_NotI_EcoRI. The amplified fragment encodes a linker sequence Nterminally of the $m(s f) g f p$ gene. The fragment was digested with BamHI and EcoRI and 
subsequently ligated into the corresponding sites of the plasmid pLOW-ftsZ-gfp to replace the original $g f p$-gene with the linker_m(sf)gfp sequence. SAOUSHSC_01908 was then amplified with primers im77_SA1908_F_SalI_RBS and im78_SA1908_R_BamHI, the product was digested with SalI and BamHI and ligated into the corresponding sites of pLOW-ftsZ-m(sf)gfp to create $\mathrm{pLOW}-s m d A-m(s f) g f p$.

\section{Construction of pMAD-smdA-m(sf)gfp aad9 for chromosomal integration. To tag the} chromosomal smdA, the plasmid pMAD-smdA-flag_aad9 was constructed initially. The insert in this plasmid (smdA-flag_aad9) was assembled by overlap extension PCR (primers im147im152), with the flag-tag sequence inserted by primer overhangs, and cloned into pMAD (34) using restriction enzymes MluI and BamHI and T4 DNA Ligase (NEB). The insert was designed so that the flag-tag could be removed using NotI and SpeI. The $m(s f) g f p$ sequence was amplified from template pMK17 (66) using the primers im153 and im154. The PCR product was digested with NotI and SpeI and subsequently ligated with NotI- and SpeI-digested pMAD-smdA-flag_aad9. The ligation mix was transformed to E. coli IM08B, and the resulting plasmid, pMAD-smdA-m(sf)gfp_aad9, was verified by sequencing and transformed into electrocompetent $S$. aureus SH1000. Integration of $s m d A-m(s f) g f p$ in the native locus of $s m d A$ using the temperature-sensitive pMAD-system was carried out as previously described (34).

Construction of pHC-ftsZ-mKate2. ftsZ-mKate2 was amplified from the plasmid pLOW-ftsZmKate2. pLOW-ftsZ-mKate2 was made in a similar manner as described for pLOW-ftsZ$m(s f) g f p$, but with reverse primer im5_mKate_R_NotI_EcoRI and genomic DNA derived from strain MK119 (67) as template for amplification of $m$ Kate2. Then, ftsZ-mKate2 was amplified with primers USHC109 and USHC148, generating a product with SalI and MluI as overhang. 
The PCR product and the plasmid pSK9065 (68) were digested with SalI and MluI and thereafter ligated.

Construction of $p L O W-s m d A-m Y F P$. This plasmid was constructed by using pLOW-ftsZ$m Y F P$ as starting point, made similarly as described for $\mathrm{pLOW}-f t s Z-m(s f) g f p$, but with reverse primer im3_cfp_myfp_R_NotI_EcoRI and plasmid pMK20 (lab collection) as template for amplifying $m Y F P$. The plasmids pLOW-smdA-m(sf)gfp (described above) and pLOW-ftsZ$m Y F P$ were digested with SalI and BamHI and subsequently ligated, resulting in pLOW-smdA$m Y F P$

\section{CRISPRi constructs}

Construction of $p C G 248-s g R N A(s m d A)$. For gene knockdowns, the CRISPR interference (CRISPRi) system developed by Stamsås et al. (69) was used. In this system, dcas 9 is placed downstream of an IPTG-inducible promoter in the plasmid pLOW-dcas 9 . A second plasmid is carrying the single guide RNA (pCG248-sgRNA $(x)$, where $x$ represents the targeted gene), which constitutively expresses the sgRNA, including the $20 \mathrm{nt}$ base-pairing region specific for the gene to be knocked down. The pLOW-dcas 9 plasmid contains an erythromycin resistance gene, and the pCG248-sgRNA(x) plasmid a chloramphenicol resistance gene. The genespecific 20 nt sequences were replaced in the pCG248-sgRNA(x) plasmids using an inverse PCR approach as described earlier (69) using primers mk299 and mk323.

Construction of $p L O W-d C a s 9$ aad9. In order to make the CRISPRi system compatible with the MRSA strain COL (which is intrinsically erythromycin resistant), the erythromycin resistance gene erm $C$ in pLOW-dcas 9 was replaced with aad , encoding a spectinomycin resistance cassette. The primers im183 and im 184 were used to amplify the entire pLOW-dcas 9 
plasmid, except the ermC gene. The aad 9 gene was amplified with primers im185 and im186 using pCN55 (70) as template, where im 185 contained the sequence of im183 as overhang, and im186 the sequence of im184 as overhang. Thus, the two fragments had overlapping sequences and were fused using NEBuilder® HiFi DNA Assembly (NEB). The construct was transformed to E. coli IM08B, and the plasmid verified by PCR and sequencing. For CRISPRi in S. aureus COL, the pLOW-dcas9_aad9 plasmid was used along with pCG248-sgRNA $(x)$.

\section{Construction of plasmids used for overexpression studies}

Construction of $p L O W-$ smdA and mutated versions. smdA was amplified from $S$. aureus genomic DNA using primers im77_SA1908_F_SalI_RBS and mk517_1908_R_NotI. The fragment was digested with SalI and NotI and ligated into the corresponding sites of plasmid pLOW-dcas9 (69) to produce the plasmid pLOW-smdA, with IPTG-inducible overexpression of $s m d A$. pLOW-smdAATMH was constructed in a similar manner, except that primer mk518_1908_F_RBS_SalI was used instead of im 77 to remove the $29 \mathrm{~N}$-terminal amino acids of SmdA, predicted to encode the TMH and extracellular part. Site-directed mutagenesis in the two plasmids was performed by a two-step overlap extension PCR approach, where the mutations were introduced in the primers. The primers mk519 and mk520 were used for introducing mutation H145A (mut1), mut2 (R150A, R151A) was made with primers mk521 and mk522, and mut3 (F280A, H281A) with primers mk529 and mk530.

\section{Phase contrast- and fluorescence microscopy analysis}

536 For induction of plasmid-encoded fluorescent fusions, exponentially growing cultures were diluted to $\mathrm{OD}_{600} 0.05$ in medium with $50 \mu \mathrm{M}$ IPTG an incubated for 2 hours prior to microscopy. For CRISPRi-knockdown and overexpression experiments, cultures of $\mathrm{OD}_{600}=$ 
approximately 0.4. For labelling of cell wall, BODIPY ${ }^{\mathrm{TM}}$ FL vancomycin (VanFL) (Invitrogen) concentration of $250 \mu \mathrm{M}$. The cells were incubated with HADA at $37^{\circ} \mathrm{C}$ for $90 \mathrm{sec}$ and then put on ice. The cultures were pelleted by centrifugation at $10000 \times g$ at $4^{\circ} \mathrm{C}$ for $1 \mathrm{~min}$, washed with cold $1 \times$ PBS, pH 7.4 and finally resuspended in $25 \mu 1$ PBS. Cells were subsequently added to agarose pads and microscopy was performed on a Zeiss AxioObserver with ZEN Blue camera (Hamamatsu Photonics) was used to capture images through a $100 \times$ PC objective. HPX 120 Illuminator (Zeiss) was used as a light source for fluorescence microscopy. prepared for publication using Fiji (71). For analysis of cell roundness, cell area and fluorescent labelling patterns, MicrobeJ (72) was used to determine cell outlines. Outlines were corrected manually, when necessary. Cell area and roundness as a measure of morphology were calculated and plotted using MicrobeJ. After cell outline detection, categorization of cells into normal or abnormal labelling patterns were done manually using images from independent experiments. The septum/periphery fluorescence signal ratio was measured as described before typical for septum-enriched proteins (11).

Structured illumination microscopy (SIM) and stimulated emission depletion (STED)

microscopy

562 Super-resolution SIM imaging was performed using a Zeiss ELYRA PS.1 microscope equipped with a $100 \times 1.46 \mathrm{NA}$ alpha plan apochromat oil immersion objective and a pco.edge 
times per image, for a total of 15 images per SIM reconstruction. All imaging was performed at room temperature $\left(\sim 23^{\circ} \mathrm{C}\right)$. Raw data were reconstructed using the SIM algorithms in ZEN 2011 SP7 software (black edition, Carl Zeiss). Brightfield images were captured using widefield imaging mode. Images had a final pixel size of $25 \mathrm{~nm}$.

Gated STED (gSTED) images were acquired on a Leica TCS SP8 STED $3 \times$ system, using an HC PL Apo $100 \times$ oil immersion objective with NA 1.40. Fluorophores were excited using a white excitation laser operated at $509 \mathrm{~nm}$ for mYFP and $563 \mathrm{~nm}$ for mKate2. A STED depletion laser line was operated at $592 \mathrm{~nm}$ and $775 \mathrm{~nm}$ for mYFP and mKate2, respectively, using a detection time-delay of $0.8-1.6 \mathrm{~ns}$ for both fluorophores. The total depletion laser intensity was in the order of $20-40 \mathrm{MW} \mathrm{cm}^{-2}$ for all STED imaging. The final pixel size was $13 \mathrm{~nm}$ and scanning speed was $400 \mathrm{~Hz}$. The pinhole size was set to $0.9 \mathrm{AU}$.

Images were processed and analyzed using Fiji (71). Line scans were analyzed using the Plot Profile function in Fiji, using a line width of 1.5. Fluorescence intensities were normalized to the highest value for each channel.

\section{Scanning- and transmission electron microscopy analysis}

Overnight cultures were diluted to approximately $\mathrm{OD}_{600}=0.1$. When $\mathrm{OD}_{600}$ reached 0.4 , the cultures were diluted 1:250. Antibiotic and IPTG were added when appropriate. The cultures $(10 \mathrm{ml})$ were grown to $\mathrm{OD}_{600}=0.3$ and 1 volume of fixation solution, containing $5 \%(\mathrm{w} / \mathrm{v})$ glutaraldehyde and $4 \%(\mathrm{w} / \mathrm{v})$ paraformaldehyde in $1 \times \mathrm{PBS}, \mathrm{pH} 7.4$, was added. The tubes were carefully inverted a few times and incubated for one hour at room temperature before being placed at $4^{\circ} \mathrm{C}$ overnight. The following day, the cultures were centrifugated at $5000 \times g$, and the pellets washed three times with PBS. Further preparations of samples to be analyzed with TEM were performed as described before (69). 

conductive layer of Au-Pd before being analyzed in a ZEISS EVO50 EP Scanning electron microscope. Images were analyzed and prepared using Fiji (71).

\section{Growth assays}

596

597

598

599

600

601

602

603

604

605

606

607

608

609

610

611

612

For examining growth on solid media, overnight cultures were diluted 1:250 in BHI containing $300 \mu \mathrm{M}$ IPTG, unless otherwise specified. When reaching exponential phase, $\mathrm{OD}_{600}$ were adjusted to 0.3 for all samples. A 10 -fold dilution series were made for all strains, and $2 \mu 1$ of each dilution were spotted on BHI agar containing proper antibiotics and $300 \mu \mathrm{M}$ IPTG. The plates were incubated at $37^{\circ} \mathrm{C}$ for approximately $16 \mathrm{~h}$, and pictures of the plates were captured in a Gel Doc ${ }^{\mathrm{TM}} \mathrm{XR}+$ Imager (Bio-Rad).

For measurement of growth in liquid cultures, cells were at $\mathrm{OD}_{600} 0.4$, were diluted 1:250 in medium containing $300 \mu \mathrm{M}$ IPTG. Every hours for five hours, $\mathrm{OD}_{600}$ was measured spectrophotometrically using Genesys 30 (Thermo Scientific) and dilutions of the cultures were plated for CFU-counting.

\section{Minimum inhibitory concentration (MIC) assays}

The experiments were set up in 96-well microtiter plates with a total volume of $300 \mu 1$. A twofold dilution series of the antibiotics were prepared in BHI containing selective antibiotics and IPTG when appropriate. The overnight cultures were diluted 1:1000 in BHI containing 300 $\mu \mathrm{g} / \mathrm{ml}$ IPTG for induction. The cells were grown at $37^{\circ} \mathrm{C}$, and the plate was shaken for $5 \mathrm{sec}$ before measurements of $\mathrm{OD}_{600}$ were taken every 10 th min throughout the experiment, using 
either a Synergy ${ }^{\mathrm{TM}}$ H1 Hybrid Multi-Mode Reader (BioTek Instruments) or a Hidex Sense

614 (Hidex Oy). The experiments were repeated at least two times with the same results.

\section{RNA isolation and RT-PCR}

To verify that $s m d A$ expression was knocked down by CRISPRi, RNA was isolated from exponentially growing cultures of IM284 (SH1000, CRISPRi(control)), IM165 (SH000 synthesis were performed as previously described (69). A PCR reaction (30 cycles) was run with Phusion ${ }^{\circledR}$ High-Fidelity DNA polymerase (NEB). The primer pairs im126/im127 and im137/im138 were used to target the reference gene $p t a(74)$ and $s m d A$, respectively.

\section{Detection of lipoteichoic acid (LTA) by Western blotting}

Detection of LTA was performed by western blotting, and sample preparations were done according to descriptions found in Hesser et al (26). The samples were separated on a 4-20\% gradient Mini Protean TGX acrylamide gel (BioRad), and subsequently transferred to a polyvinylidene difluoride (PVDF) membrane by semi-dry electroblotting. The membrane was blocked for $1 \mathrm{~h}$ in $5 \%(\mathrm{w} / \mathrm{v})$ skim milk in PBST and placed overnight at $4^{\circ} \mathrm{C}$. Next, the membrane was incubated for $1 \mathrm{~h}$ with $\alpha$-LTA (Hycult) 1:4000 in PBST, washed three times (10 minutes each) with PBST before incubation for $1 \mathrm{~h}$ with $\alpha$-Mouse IgG HRP Conjugate (Promega) secondary antibody (1:10 000 in PBST). The membrane was again washed three times and LTA bands were visualized by using SuperSignal $^{\mathrm{TM}}$ West Pico PLUS

634 Chemiluminescent substrate (Thermo Fisher Scientific) in an Azure Imager c400 (Azure Biosystems). medium. The supernatants, after harvesting cells during sample preparations, were kept. 
Supernatant samples were centrifugated for $16000 \times g$ for $10 \mathrm{~min}$, and $75 \mu 1$ was mixed with $25 \mu 14 \times$ SDS-PAGE sample buffer. These samples were boiled for $30 \mathrm{~min}$ and applied on the 4-20 \% Mini Protean TGX acrylamide gel. Thereafter, the same immunodetection procedure as described above was followed.

\section{Fourier-transform infrared spectroscopy (FTIR) analysis}

Cultures of the strains IM313 (HG001, CRISPRi(control)), IM312 (HG001, CRISPRi(smdA)) and IM357 (HG001, CRISPRi(tarO)) were initially pre-grown to exponential phase, back diluted to $\mathrm{OD}_{600}=0.05$ and induced with $300 \mu \mathrm{M}$ IPTG. The bacterial cells $(1 \mathrm{ml})$ were harvested at $\mathrm{OD}_{600}=0.4$ by centrifugation at $5000 \times g, 4^{\circ} \mathrm{C}$, for $3 \mathrm{~min}$. The pelleted cells were kept at $-20^{\circ} \mathrm{C}$ prior to further processing. Pellets were resuspended in $40 \mu 10.1 \%(\mathrm{w} / \mathrm{v}) \mathrm{NaCl}$, and $10 \mu 1$ of the suspensions were added to an IR-light-transparent silicon 384-well microplate (Bruker Optic, Germany), with three technical replicates for each sample. The plates were left to dry at room temperature for approximately $2 \mathrm{~h}$. FTIR spectra were recorded in transmission mode using a high-throughput screening extension (HTS-XT) unit coupled to a Vertex 70 FTIR spectrometer (Bruker Optik GmbH, Leipzig, Germany). Spectra were recorded in the region $4000-500 \mathrm{~cm}^{-1}$, with a spectral resolution of $6 \mathrm{~cm}^{-1}$, a digital spacing of $1.928 \mathrm{~cm}^{-1}$, and an aperture of $5 \mathrm{~mm}$. For each spectrum, 64 scans were averaged. The OPUS software (Bruker Optik GmbH, Leipzig,Germany) was used for data acquisition and instrument control. The obtained spectra were processed by taking second derivatives and extended multiplicative signal correction (EMSC) preprocessing in Unscrambler X version 11 (CAMO Analytics, Oslo, Norway). Results presented are averaged spectra from 3 biological replicates (each with 3 technical replicates) for the region with wavelengths between $1200 \mathrm{~cm}^{-1}$ and $800 \mathrm{~cm}^{-1}$. 

phase, back diluted to $\mathrm{OD}_{600}=0.05$ and induced if necessary. When reaching $\mathrm{OD}_{600}$ at $0.4,80$ $\mathrm{ml}$ of each culture were harvested by centrifugation at $4000 \times g, 4^{\circ} \mathrm{C}$ for $3 \mathrm{~min}$. Supernatants were decanted and pellets resuspended in cold TBS prior to transfer to $1.5 \mathrm{ml}$ microcentrifuge tubes. Centrifugation was repeated for $1 \mathrm{~min}$, and pelleted cells were stored at $-80^{\circ} \mathrm{C}$ prior to further use. transferred to $2 \mathrm{ml}$ lysing matrix B tubes (MP Biomedicals) containing $0.8 \mathrm{~g} \leq 106 \mu \mathrm{m}$ glass beads (Sigma-Aldrich) and subjected for mechanical lysis by agitation in a FastPrep- $24^{\mathrm{TM}}$ (MP Biomedicals) for $3 \times 30 \mathrm{sec}$ at $6.5 \mathrm{~m} / \mathrm{s}$, with $1 \mathrm{~min}$ pause on ice between the runs. Tubes were centrifugated at $5000 \times \mathrm{g}, 4^{\circ} \mathrm{C}$ for $10 \mathrm{~min}$, and supernatants transferred to new tubes. Concentrations were determined measuring Abs280 using NanoDrop ${ }^{\text {TM }} 2000$ (Thermo Fisher Scientific), where a small amount of the samples were added a final concentration of $1 \%(\mathrm{w} / \mathrm{v})$ SDS prior to measurements. GFP-Trap beads (25 $\mu 1$ per sample) (Chromotek) were washed three times with $500 \mu \mathrm{l}$ ice cold Dilution/Wash buffer $(10 \mathrm{mM}$ Tris $\mathrm{pH} 7.5,150 \mathrm{mM} \mathrm{NaCl}, 0.5$ $\mathrm{mM}$ EDTA) and centrifugated at $2500 \times g, 4^{\circ} \mathrm{C}$ for $5 \mathrm{~min}$. Lysates were diluted in Dilution/Wash buffer to a final concentration of $1 \mathrm{mg}$ in a total volume of $500 \mu \mathrm{l}$, before being transferred to GFP-Trap beads. Samples were placed in a Bio RS-24 Multi rotor (Biosan) at $4^{\circ} \mathrm{C}$ for $1 \mathrm{~h}$. Then, samples were centrifugated at $2500 \times g, 4^{\circ} \mathrm{C}$ for $5 \mathrm{~min}$, supernatant removed, and beads washed three times with Dilution/Wash buffer. During last washing step, solutions were transferred to new tubes, and after centrifugation and removal of supernatant, beads were resuspended in $50 \mu 15 \%(\mathrm{w} / \mathrm{v}) \mathrm{SDS}, 50 \mathrm{mM}$ Tris $\mathrm{pH}$ 7.6. Tubes were incubated at $95^{\circ} \mathrm{C}$ for 5 
min, and centrifugated at maximum speed for $30 \mathrm{sec}$. After standing at the bench a few minutes, 30-50 $\mu 1$ were transferred into new tubes. Samples were kept at $-20^{\circ} \mathrm{C}$ and heated for $2 \mathrm{~min}$ at $95^{\circ} \mathrm{C}$ prior to the sample preparation method Suspension trapping (STrap), conducted as described by A. Zougman et al. (75).

The peptide samples were analyzed by coupling a nano UPLC (nanoElute, Bruker) to a trapped ion mobility spectrometry/quadrupole time of flight mass spectrometer (timsTOF Pro, Bruker). The peptides were separated by an Aurora Series $1.6 \mu \mathrm{m}$ C18 reverse-phase $25 \mathrm{~cm} \times$ $75 \mu \mathrm{m}$ analytical column with nanoZero and CaptiveSpray Insert (IonOpticks, Australia). The flow rate was set to $400 \mathrm{nl} / \mathrm{min}$ and the peptides were separated using a gradient from $2 \%$ to $95 \%$ acetonitrile solution (in $0.1 \%(\mathrm{v} / \mathrm{v})$ formic acid) over 120 minutes. The timsTOF Pro was ran in positive ion data dependent acquisition PASEF mode, with a mass range at 100-1700 $\mathrm{m} / \mathrm{z}$. The acquired spectra were analyzed against a $S$. aureus NCTC 8325 proteome database.

\section{Bacterial two-hybrid (BACTH) assays}

Plasmid construction, and procedure for the BACTH assays, were conducted in a same manner as previously described (69), and primers used are listed in Table S3. Briefly, gene fusions of selected genes, to the T18 or T25 domains of adenylate cyclase form Bordetella pertussis, were made by restriction cutting and ligation in the plasmid vectors pKT25, pKNT25, pUT18 or pUT18C (Euromedex). E. coli XL1-Blue cells were used for transformation, and plasmids verified by sequencing before BACTH assays (76) were set up according to the manufacturer (Euromedex). Co-transformation of plasmids containing fusion-genes of opposite domains, that is T25 in one plasmid and T18 in the other, were done in E. coli BTH101 with $50 \mu \mathrm{g} / \mathrm{ml}$ kanamycin and $100 \mu \mathrm{g} / \mathrm{ml}$ ampicillin as selection markers. Five random colonies were picked, grown in liquid LB to visible growth, and spotted on LA plates containing $40 \mu \mathrm{g} / \mathrm{ml} \mathrm{X-gal} \mathrm{and}$ $0.5 \mathrm{mM}$ IPTG, in addition to the selection markers. Plates were incubated dark at $30^{\circ} \mathrm{C}$ for 20 - 
bioRxiv preprint doi: https://doi org/10.1101/2021.1123,469651: this version posted February 12 2022. The copyright holder for this preprint (which was not certified by peer review) is the author/funder, who has granted bioRxiv a license to display the preprint in perpetuity. It is made available under aCC-BY-NC-ND 4.0 International license.

712

713

714

\section{Acknowledgements}

716 We would like to acknowledge the NMBU Imaging Center for help with electron microscopy,

$48 \mathrm{~h}$ before being inspected, and blue colonies are an indication of positive interaction between tested genes. Presented results are representative for at least six independent replicates.

Maria Victoria Heggenhougen and Marita Torrissen Mårli (both NMBU) for access to unpublished strains and Henriette Olsen (NMBU) for help with FTIR. Mass spectrometrybased proteomic analyses were performed by The MS and Proteomics Core Facility, Norwegian University of Life Sciences (NMBU). This facility is a member of the National Network of Advanced Proteomics Infrastructure (NAPI), which is funded by the Research Council of Norway INFRASTRUKTUR-program (project number: 295910). We acknowledge the van Nieuwenhze group, Indiana University, for providing HADA. The work is supported by grants from the Research Council of Norway (project number 250976) and JPI-AMR (project number 296906). Work in the Structural Cell Biology Unit (OIST) is supported by OIST core subsidy. Ine S. Myrbråten acknowledge support from "Pasteurlegatet". 


\section{References}

1. Sass P, Brötz-Oesterhelt H. 2013. Bacterial cell division as a target for new antibiotics. Curr Opin Microbiol 16:522-530.

2. Pinho MG, Kjos M, Veening J-W. 2013. How to get (a) round: mechanisms controlling growth and division of coccoid bacteria. Nat Rev Microbiol 11:601-614.

3. Errington J, Daniel RA, Scheffers D-J. 2003. Cytokinesis in bacteria. Microbiol Mol Biol Rev 67:52-65.

4. Saraiva BM, Sorg M, Pereira AR, Ferreira MJ, Caulat LC, Reichmann NT, Pinho MG. 2020. Reassessment of the distinctive geometry of Staphylococcus aureus cell division. Nat Comm 11:1-7.

5. Veiga H, Jorge AM, Pinho MG. 2011. Absence of nucleoid occlusion effector Noc impairs formation of orthogonal FtsZ rings during Staphylococcus aureus cell division. Mol Microbiol 80:1366-1380.

6. Gallay C, Sanselicio S, Anderson ME, Soh YM, Liu X, Stamsås GA, Pelliciari S, van Raaphorst R, Dénéréaz J, Kjos M, Murray H, Gruber S, Grossman AD, Veening JW. 2021. CcrZ is a pneumococcal spatiotemporal cell cycle regulator that interacts with FtsZ and controls DNA replication by modulating the activity of DnaA. Nat Microbiol 6:1175-1187.

7. Barreteau H, Kovač A, Boniface A, Sova M, Gobec S, Blanot D. 2008. Cytoplasmic steps of peptidoglycan biosynthesis. FEMS Microbiol Rev 32:168-207.

8. Bouhss A, Trunkfield AE, Bugg TD, Mengin-Lecreulx D. 2007. The biosynthesis of peptidoglycan lipid-linked intermediates. FEMS Microbiol Rev 32:208-233.

9. Rohrer S, Berger-Bächi B. 2003. FemABX peptidyl transferases: a link between branched-chain cell wall peptide formation and $\beta$-lactam resistance in gram-positive cocci. Antimicrob Agents Chemother 47:837-846.

10. Sham L-T, Butler EK, Lebar MD, Kahne D, Bernhardt TG, Ruiz N. 2014. Bacterial cell wall. MurJ is the flippase of lipid-linked precursors for peptidoglycan biogenesis. Science 345:220-222.

11. Monteiro JM, Pereira AR, Reichmann NT, Saraiva BM, Fernandes PB, Veiga H, Tavares AC, Santos M, Ferreira MT, Macario V, VanNieuwenhze MS, Filipe SR, Pinho MG. 2018. Peptidoglycan synthesis drives an FtsZ-treadmilling-independent step of cytokinesis. Nature 554:528-532. 
12. Reichmann NT, Tavares AC, Saraiva BM, Jousselin A, Reed P, Pereira AR, Monteiro JM, VanNieuwenhze MS, Fernandes F, Pinho MG. 2019. SEDS-bPBP pairs direct lateral and septal peptidoglycan synthesis in Staphylococcus aureus. Nat Microbiol 4:1368-1377.

13. Meeske AJ, Riley EP, Robins WP, Uehara T, Mekalanos JJ, Kahne D, Walker S, Kruse AC, Bernhardt TG, Rudner DZ. 2016. SEDS proteins are a widespread family of bacterial cell wall polymerases. Nature 537:634-638.

14. Wyke AW, Ward JB, Hayes MV, Curtis NA. 1981. A role in vivo for penicillin-binding protein-4 of Staphylococcus aureus. Eur J Biochem 119:389-393.

15. Atilano ML, Pereira PM, Yates J, Reed P, Veiga H, Pinho MG, Filipe SR. 2010. Teichoic acids are temporal and spatial regulators of peptidoglycan cross-linking in Staphylococcus aureus. Proc Natl Acad Sci U S A 107:18991-18996.

16. Pinho MG, Errington J. 2005. Recruitment of penicillin-binding protein PBP2 to the division site of Staphylococcus aureus is dependent on its transpeptidation substrates. Mol Microbiol 55:799-807.

17. Hartman BJ, Tomasz A. 1984. Low-affinity penicillin-binding protein associated with beta-lactam resistance in Staphylococcus aureus. J Bacteriol 158:513-516.

18. Ubukata K, Yamashita N, Konno M. 1985. Occurrence of a beta-lactam-inducible penicillin-binding protein in methicillin-resistant staphylococci. Antimicrob Agents Chemother 27:851-857.

19. Oshida T, Sugai M, Komatsuzawa H, Hong Y-M, Suginaka H, Tomasz A. 1995. A Staphylococcus aureus autolysin that has an N-acetylmuramoyl-L-alanine amidase domain and an endo-beta-N-acetylglucosaminidase domain: cloning, sequence analysis, and characterization. Proc Natl Acad Sci U S A 92:285-289.

20. Nega M, Tribelli PM, Hipp K, Stahl M, Götz F. 2020. New insights in the coordinated amidase and glucosaminidase activity of the major autolysin (Atl) in Staphylococcus aureus. Commun Biol 3:1-10.

21. Thalsø-Madsen I, Torrubia FR, Xu L, Petersen A, Jensen C, Frees D. 2019. The Sle1 cell wall amidase is essential for $\beta$-lactam resistance in community-acquired methicillin-resistant Staphylococcus aureus USA300. Antimicrob Agents Chemother 64:e01931-19.

22. Dubrac S, Boneca IG, Poupel O, Msadek T. 2007. New insights into the WalK/WalR (YycG/YycF) essential signal transduction pathway reveal a major role in controlling 
cell wall metabolism and biofilm formation in Staphylococcus aureus. J Bacteriol 189:8257-69.

23. Zhou X, Halladin DK, Rojas ER, Koslover EF, Lee TK, Huang KC, Theriot JA. 2015. Mechanical crack propagation drives millisecond daughter cell separation in Staphylococcus aureus. Science 348:574-578.

24. Monteiro JM, Fernandes PB, Vaz F, Pereira AR, Tavares AC, Ferreira MT, Pereira PM, Veiga H, Kuru E, VanNieuwenhze MS. 2015. Cell shape dynamics during the staphylococcal cell cycle. Nat Comm 6:1-12.

25. Brown S, Santa Maria Jr JP, Walker S. 2013. Wall teichoic acids of Gram-positive bacteria. Ann Rev Microbiol 67:313-336.

26. Hesser AR, Matano LM, Vickery CR, Wood BM, Santiago AG, Morris HG, Do T, Losick R, Walker S. 2020. The length of lipoteichoic acid polymers controls Staphylococcus aureus cell size and envelope integrity. J Bacteriol 202:e0149-20.

27. Silber N, Pan S, Schäkermann S, Mayer C, Brötz-Oesterhelt H, Sass P. 2020. Cell division protein FtsZ is unfolded for $\mathrm{N}$-terminal degradation by antibiotic-activated ClpP. mBio 11:e01006-20.

28. Feng J, Michalik S, Varming AN, Andersen JH, Albrecht D, Jelsbak L, Krieger S, Ohlsen K, Hecker M, Gerth U, Ingmer H, Frees D. 2013. Trapping and proteomic identification of cellular substrates of the ClpP protease in Staphylococcus aureus. J Proteome Res 12:547-58.

29. Jensen C, Bæk KT, Gallay C, Thalsø-Madsen I, Xu L, Jousselin A, Torrubia FR, Paulander W, Pereira AR, Veening J-W. 2019. The ClpX chaperone controls autolytic splitting of Staphylococcus aureus daughter cells, but is bypassed by $\beta$-lactam antibiotics or inhibitors of WTA biosynthesis. PLoS Pathog 15:e1008044.

30. Chaudhuri RR, Allen AG, Owen PJ, Shalom G, Stone K, Harrison M, Burgis TA, Lockyer M, Garcia-Lara J, Foster SJ, Pleasance SJ, Peters SE, Makell DJ, Charles IG. 2009. Comprehensive identification of essential Staphylococcus aureus genes using Transposon-Mediated Differential Hybridisation (TMDH). BMC Genomics 10:291.

31. Santiago M, Matano LM, Moussa SH, Gilmore MS, Walker S, Meredith TC. 2015. A new platform for ultra-high density Staphylococcus aureus transposon libraries. BMC Genomics 16:1-18.

32. Valentino MD, Foulston L, Sadaka A, Kos VN, Villet RA, Santa Maria J, Lazinski DW, Camilli A, Walker S, Hooper DC. 2014. Genes contributing to Staphylococcus aureus fitness in abscess-and infection-related ecologies. mBio 5:e1729-14. 
33. Grynberg M, Godzik A. 2004. NERD: a DNA processing-related domain present in the anthrax virulence plasmid, pXO1. Trends Biochem Sci 29:106-110.

34. Arnaud M, Chastanet A, Débarbouillé M. 2004. New vector for efficient allelic replacement in naturally nontransformable, low-GC-content, Gram-positive bacteria. Appl Environ Microbiol 70:6887-6891.

35. Liew AT, Theis T, Jensen SO, Garcia-Lara J, Foster SJ, Firth N, Lewis PJ, Harry EJ. 2011. A simple plasmid-based system that allows rapid generation of tightly controlled gene expression in Staphylococcus aureus. Microbiology 157:666-676.

36. Reynolds PE. 1989. Structure, biochemistry and mechanism of action of glycopeptide antibiotics. Eur J Clin Microbiol Infect Dis 8:943-950.

37. Campbell J, Singh AK, Santa Maria Jr JP, Kim Y, Brown S, Swoboda JG, Mylonakis E, Wilkinson BJ, Walker S. 2011. Synthetic lethal compound combinations reveal a fundamental connection between wall teichoic acid and peptidoglycan biosyntheses in Staphylococcus aureus. ACS Chem Biol 6:106-116.

38. Campbell J, Singh AK, Swoboda JG, Gilmore MS, Wilkinson BJ, Walker S. 2012. An antibiotic that inhibits a late step in wall teichoic acid biosynthesis induces the cell wall stress stimulon in Staphylococcus aureus. Antimicrob Agents Chemother 56:1810-20.

39. Vickery CR, Wood BM, Morris HG, Losick R, Walker S. 2018. Reconstitution of Staphylococcus aureus lipoteichoic acid synthase activity identifies Congo red as a selective inhibitor. J Am Chem Soc 140:876-879.

40. Price NP, Tsvetanova B. 2007. Biosynthesis of the tunicamycins: a review. J Antibiot $60: 485-491$.

41. Swoboda JG, Campbell J, Meredith TC, Walker S. 2010. Wall teichoic acid function, biosynthesis, and inhibition. Chembiochem 11:35-45.

42. Santa Maria JP, Jr., Sadaka A, Moussa SH, Brown S, Zhang YJ, Rubin EJ, Gilmore MS, Walker S. 2014. Compound-gene interaction mapping reveals distinct roles for Staphylococcus aureus teichoic acids. Proc Natl Acad Sci U S A 111:12510-12515.

43. Oku Y, Kurokawa K, Matsuo M, Yamada S, Lee B-L, Sekimizu K. 2009. Pleiotropic roles of polyglycerolphosphate synthase of lipoteichoic acid in growth of Staphylococcus aureus cells. J Bacteriol 191:141-151.

44. Mikkelsen K, Sirisarn W, Alharbi O, Alharbi M, Liu H, Nøhr-Meldgaard K, Mayer K, Vestergaard M, Gallagher LA, Derrick JP. 2021. The novel membrane-associated auxiliary factors AuxA and AuxB modulate $\beta$-lactam resistance in MRSA by stabilizing lipoteichoic acids. Int J Antimicrob Agents 57:106283. 
45. Suzuki T, Campbell J, Kim Y, Swoboda JG, Mylonakis E, Walker S, Gilmore MS. 2012. Wall teichoic acid protects Staphylococcus aureus from inhibition by Congo red and other dyes. J Antimicrob Chemother 67:2143-2151.

46. Chan YG-Y, Kim HK, Schneewind O, Missiakas D. 2014. The capsular polysaccharide of Staphylococcus aureus is attached to peptidoglycan by the LytR-CpsA-Psr (LCP) family of enzymes. J Biol Chem 289:15680-15690.

47. Grunert T, Jovanovic D, Sirisarn W, Johler S, Weidenmaier C, Ehling-Schulz M, Xia G. 2018. Analysis of Staphylococcus aureus wall teichoic acid glycoepitopes by Fourier Transform Infrared Spectroscopy provides novel insights into the staphylococcal glycocode. Sci Rep 8:1-9.

48. Radkov AD, Hsu Y-P, Booher G, VanNieuwenhze MS. 2018. Imaging bacterial cell wall biosynthesis. Annu Rev Biochem 87:991-1014.

49. Biswas R, Voggu L, Simon UK, Hentschel P, Thumm G, Götz F. 2006. Activity of the major staphylococcal autolysin Atl. FEMS Microbiol Letters 259:260-268.

50. Jorge AM, Hoiczyk E, Gomes JP, Pinho MG. 2011. EzrA contributes to the regulation of cell size in Staphylococcus aureus. PLoS One 6:e27542.

51. Lund VA, Wacnik K, Turner RD, Cotterell BE, Walther CG, Fenn SJ, Grein F, Wollman AJ, Leake MC, Olivier N, Cadby A, Mesnage S, Jones S, Foster SJ. 2018. Molecular coordination of Staphylococcus aureus cell division. eLife 7:e32057.

52. Jumper J, Evans R, Pritzel A, Green T, Figurnov M, Ronneberger O, Tunyasuvunakool K, Bates R, Žídek A, Potapenko A, Bridgland A, Meyer C, Kohl SAA, Ballard AJ, Cowie A, Romera-Paredes B, Nikolov S, Jain R, Adler J, Back T, Petersen S, Reiman D, Clancy E, Zielinski M, Steinegger M, Pacholska M, Berghammer T, Bodenstein S, Silver D, Vinyals O, Senior AW, Kavukcuoglu K, Kohli P, Hassabis D. 2021. Highly accurate protein structure prediction with AlphaFold. Nature 596:583-589.

53. Roemer T, Schneider T, Pinho MG. 2013. Auxiliary factors: a chink in the armor of MRSA resistance to $\beta$-lactam antibiotics. Curr Opin Microbiol 16:538-548.

54. Tan CM, Therien AG, Lu J, Lee SH, Caron A, Gill CJ, Lebeau-Jacob C, BentonPerdomo L, Monteiro JM, Pereira PM, Elsen NL, Wu J, Deschamps K, Petcu M, Wong S, Daigneault E, Kramer S, Liang L, Maxwell E, Claveau D, Vaillancourt J, Skorey K, Tam J, Wang H, Meredith TC, Sillaots S, Wang-Jarantow L, Ramtohul Y, Langlois E, Landry F, Reid JC, Parthasarathy G, Sharma S, Baryshnikova A, Lumb KJ, Pinho MG, Soisson SM, Roemer T. 2012. Restoring methicillin-resistant Staphylococcus aureus susceptibility to $\beta$-lactam antibiotics. Sci Transl Med 4:126ra35. 
55. Lee SH, Jarantow LW, Wang H, Sillaots S, Cheng H, Meredith TC, Thompson J, Roemer T. 2011. Antagonism of chemical genetic interaction networks resensitize MRSA to $\beta$-lactam antibiotics. Chem Biol 18:1379-1389.

56. Brown S, Xia G, Luhachack LG, Campbell J, Meredith TC, Chen C, Winstel V, Gekeler C, Irazoqui JE, Peschel A. 2012. Methicillin resistance in Staphylococcus aureus requires glycosylated wall teichoic acids. Proc Natl Acad Sci U S A 109:18909-18914.

57. Quiblier C, Zinkernagel AS, Schuepbach RA, Berger-Bächi B, Senn MM. 2011. Contribution of SecDF to Staphylococcus aureus resistance and expression of virulence factors. BMC Microbiol 11:72.

58. Roch M, Lelong E, Panasenko OO, Sierra R, Renzoni A, Kelley WL. 2019. Thermosensitive PBP2a requires extracellular folding factors PrsA and HtrA1 for Staphylococcus aureus MRSA $\beta$-lactam resistance. Commun Biol 2:417.

59. Pereira AR, Hsin J, Król E, Tavares AC, Flores P, Hoiczyk E, Ng N, Dajkovic A, Brun YV, VanNieuwenhze MS, Roemer T, Carballido-Lopez R, Scheffers DJ, Huang KC, Pinho MG. 2016. FtsZ-dependent elongation of a coccoid bacterium. mBio 7:e0090816.

60. Steele VR, Bottomley AL, Garcia-Lara J, Kasturiarachchi J, Foster SJ. 2011. Multiple essential roles for EzrA in cell division of Staphylococcus aureus. Mol Microbiol $80: 542-55$.

61. Steczkiewicz K, Muszewska A, Knizewski L, Rychlewski L, Ginalski K. 2012. Sequence, structure and functional diversity of PD-(D/E)XK phosphodiesterase superfamily. Nucleic Acids Res 40:7016-7045.

62. Kwon A, Scott S, Taujale R, Yeung W, Kochut KJ, Eyers PA, Kannan N. 2019. Tracing the origin and evolution of pseudokinases across the tree of life. Sci Signal 12:eaav3810.

63. Herbert S, Ziebandt AK, Ohlsen K, Schafer T, Hecker M, Albrecht D, Novick R, Gotz F. 2010. Repair of global regulators in Staphylococcus aureus 8325 and comparative analysis with other clinical isolates. Infect Immun 78:2877-89.

64. Monk IR, Tree JJ, Howden BP, Stinear TP, Foster TJ. 2015. Complete bypass of restriction systems for major Staphylococcus aureus lineages. mBio 6:e00308-15.

65. Löfblom J, Kronqvist N, Uhlén M, Ståhl S, Wernérus H. 2007. Optimization of electroporation-mediated transformation: Staphylococcus carnosus as model organism. J Appl Microbiol 102:736-747. 
66. van Raaphorst R, Kjos M, Veening J-W. 2017. Chromosome segregation drives division site selection in Streptococcus pneumoniae. Proc Natl Acad Sci U S A 114:E5959-E5968.

67. Kjos M, Veening JW. 2014. Tracking of chromosome dynamics in live Streptococcus pneumoniae reveals that transcription promotes chromosome segregation. Mol Microbiol 91:1088-105.

68. Brzoska AJ, Firth N. 2013. Two-plasmid vector system for independently controlled expression of green and red fluorescent fusion proteins in Staphylococcus aureus. Appl Environ Microbiol 79:3133-3136.

69. Stamsås GA, Myrbråten IS, Straume D, Salehian Z, Veening JW, Håvarstein LS, Kjos M. 2018. CozEa and CozEb play overlapping and essential roles in controlling cell division in Staphylococcus aureus. Mol Microbiol 109:615-632.

70. Charpentier E, Anton AI, Barry P, Alfonso B, Fang Y, Novick RP. 2004. Novel cassette-based shuttle vector system for Gram-positive bacteria. Appl Environ Microbiol 70:6076-6085.

71. Schindelin J, Arganda-Carreras I, Frise E, Kaynig V, Longair M, Pietzsch T, Preibisch S, Rueden C, Saalfeld S, Schmid B. 2012. Fiji: an open-source platform for biologicalimage analysis. Nat Methods 9:676-682.

72. Ducret A, Quardokus EM, Brun YV. 2016. MicrobeJ, a tool for high throughput bacterial cell detection and quantitative analysis. Nat Microbiol 1:16077.

73. Pereira PM, Filipe SR, Tomasz A, Pinho MG. 2007. Fluorescence ratio imaging microscopy shows decreased access of vancomycin to cell wall synthetic sites in vancomycin-resistant Staphylococcus aureus. Antimicrob Agents Chemother 51:362733.

74. Valihrach L, Demnerova K. 2012. Impact of normalization method on experimental outcome using RT-qPCR in Staphylococcus aureus. J Microbiol Methods 90:214-216.

75. Zougman A, Selby PJ, Banks RE. 2014. Suspension trapping (STrap) sample preparation method for bottom-up proteomics analysis. Proteomics 14:1006-1000.

76. Karimova G, Pidoux J, Ullmann A, Ladant D. 1998. A bacterial two-hybrid system based on a reconstituted signal transduction pathway. Proc Natl Acad Sci U S A 95:5752-6.

77. Omasits U, Ahrens CH, Müller S, Wollscheid B. 2014. Protter: interactive protein feature visualization and integration with experimental proteomic data. Bioinformatics 30:884-886. 
bioRxiv preprint doi: https://doi.org/10.1101/2021.11.23.469651; this version posted February $12,2022$. The copyright holder for this preprint (which was not certified by peer review) is the author/funder, who has granted bioRxiv a license to display the preprint in perpetuity. It is made available under aCC-BY-NC-ND 4.0 International license.

962

963

964

965

966

78. Sievers F, Wilm A, Dineen D, Gibson TJ, Karplus K, Li W, Lopez R, McWilliam H, Remmert M, Söding J, Thompson JD, Higgins DG. 2011. Fast, scalable generation of high-quality protein multiple sequence alignments using Clustal Omega. Mol Syst Biol 7:539. 
967

968

969

970

971

972

973

974

975

976

977

978

979

980

981

982

983

984

985

986

987

988

989

990

\section{Figures and figure legends}

Fig. 1. Phenotypes resulting from depletion of SmdA. (A) Predicted topology of SmdA using Protter (77). SmdA is predicted to have one transmembrane (TM) helix with a short extracellular N-terminus and a large intracellular domain. The sequence with predicted similarity to the NERD domain is highlighted in yellow. (B) Growth on solid media of SmdA knockdown strains (SmdA ${ }^{\text {down}) ~ i n ~ S . ~ a u r e u s ~ S H 1000 ~(I M 269), ~ N C T C 8325-4 ~(I M 311), ~ H G 001 ~}$ (IM312) and COL (IM294). Strains carrying a non-targeting sgRNA were used as controls (IM284, IM307, IM313 and IM295 for the respective strains). From non-induced overnight cultures, 10 -fold dilution series were made and spotted onto plates with $300 \mu \mathrm{M}$ isopropyl- $\beta$ D-thiogalactopyranoside (IPTG). (C) SmdA down (IM269) and control strain (IM284) analyzed by phase contrast- and fluorescence microscopy of cells stained with the cell wall label VanFL. White arrows point at mis-shaped cells and cells with perturbed septum formation. Magnified insets of representative cells are shown for the VanFL micrographs. Scale bars, $5 \mu \mathrm{m}$. (D) Fraction of cells with multiple septa per cell for the SmdA ${ }^{\text {down }}$ strain IM269 $(n=225)$ and the non-target control strain IM284 $(\mathrm{n}=242)$ are plotted. The asterisks indicate significant difference (Fisher's exact test, $\mathrm{P}<0.001$ ). (E) Cell roundness, as determined using MicrobeJ, was used as a measure of the morphology of the cells. Spherical cells will have values close to 1. Cell roundness measures for the control strain IM284 $(n=198)$ and the SmdA ${ }^{\text {down }}$ strain IM269 $(\mathrm{n}=191)$ are plotted. $(\mathbf{F})$ Cell area (in $\left.\mu \mathrm{m}^{2}\right)$ as determined using MicrobeJ of the control strain IM284 $(n=198)$ and the SmdA ${ }^{\text {down }}$ strain IM269 $(n=191)$. In E and F, significant differences between the distributions are indicted by asterisks $(* *, \mathrm{P}<0.001)$. P-values were derived from a Mann-Whitney test. 
Fig. 2. Smd $\mathrm{A}^{\text {down }}$ in S. aureus SH1000 visualized by electron microscopy. (A) Transmission

992

993

994

995

996

997

998

999

1000

1001

1002

1003

1004

1005

1006

1007

1008

1009

1010

1011

1012

1013

1014

1015

electron- and (B) scanning electron micrographs of SH1000 CRISPRi control strain (IM284) and SH1000 SmdA ${ }^{\text {down }}$ (IM269). In (A), red arrows in the TEM micrographs point at lysed cells. Representative examples of cells with parallel septa or multiple septa are shown. Green arrows point to initiation of septum synthesis at multiple sites within the same cell. Different magnifications are shown, indicated by the scale bars.

Fig. 3. SmdA interacts with important cell division proteins and is necessary for proper localization of EzrA and peptidoglycan synthesis. (A) Protein-protein interactions tested with bacterial two-hybrid assays, where SmdA and SmdA $\triangle T$ TMH were tested against PBP1, PBP2, PBP3 and EzrA. The proteins were fused to the T18 or T25 domains as indicated. Blue bacterial spots and plus symbols indicate positive interactions and white spots and minus symbols indicate no interaction. (B-D). Micrographs of HADA labelled S. aureus NCTC83254 with depletion and overexpression of SmdA. Arrows point at cells with misplaced septum synthesis. Scale bars, $2 \mu$ m. (B) CRISPRi control strain, IM307 (C) SmdA ${ }^{\text {down }}$ strain, IM311 and (D) SmdA overexpression strain, MK1866. (E) Frequency plot of cells with normal or abnormal HADA labelling pattern. Categorization of normal or abnormal labelling patterns are indicated. The number of cells analyzed were 259,179 and 189 for B, C and D, respectively. The asterisks indicate significant difference from the control (Fisher's exact test, $\mathrm{P}<0.001)$. (F) Micrographs showing co-localization of EzrA-GFP and HADA incorporation in $S$. aureus SH1000 strains with (MK1952) or without (MK1953) knockdown of SmdA. Phase contrastand fluorescence images of HADA labelling and GFP (EzrA-GFP) are shown. Scale bars, 2 $\mu \mathrm{m}$. Arrows point to cells with abnormal localization of both HADA and EzrA-GFP. (G) Frequencies of cells (from F) with normal or abnormal localization of HADA and EzrA-GFP are plotted. The number of cells analyzed were 285 (for MK1953) and 298 (for MK1952). The 
asterisks indicate significant difference form the respective controls (Fisher's exact test, $\mathrm{P}<0.001)$.

Fig. 4. Autolysis of S. aureus SH1000 depletion strains (control = IM284; WalR ${ }^{\text {down }}=\mathrm{IM} 293$;

$\left.\mathrm{SmdA}^{\text {down }}=\mathrm{IM} 269\right)$ measured in presence of (A) $0.5 \%$ Triton X-100 and (B) $100 \mathrm{ng} / \mathrm{ml}$ lysostaphin. Results presented as $\%$ of initial $\mathrm{OD}_{600}$. Error bars represent standard error calculated from four technical replicates.

Fig. 5. Subcellular localization analysis of SmdA. (A) Micrographs of cells with induced expression of SmdA-m(sf)GFP from plasmid (top panel, IM104), native chromosomal expression of the SmdA-m(sf)GFP fusion protein (middle panel, IM308), and expression of SmdA $\Delta$ TMH-m(sf)GFP from plasmid (bottom panel, IM373). Scale bars, $2 \mu \mathrm{m}$. (B) SIM images of fixed S. aureus SH1000 with plasmid-expressed SmdA-mYFP and FtsZ-mKate2 (HC060). (B-I) Side-view of a cell showing that FtsZ localizes at septum before arrival of SmdA. As cell division progresses, (B-II) SmdA concentrates at sites where septum formation is initiated, and (B-III) displays a septal localization at the two septal membranes as FtsZ constricts and septum formation proceeds. (B-IV) Top-view of a cell showing the FtsZ-ring inside of the SmdA-ring. All scale bars, $0.5 \mu \mathrm{m}$. (C) STED images of fixed S. aureus SH1000 with plasmid-expressed SmdA-mYFP and FtsZ-mKate2 (HC060), where line scans show fluorescence intensity of selected areas. (C-I) At an early stage of cell division, the rings of both SmdA and FtsZ have a similar diameter, but do not overlap in their distribution, and a heterogenous distribution with a patchy signal is observed. (C-II) Top-view of a cell as cell division progresses, with the FtsZ-ring laying inside of SmdA, approximately 100-150 nm apart from each other. (C-III) Side-view of a cell showing how FtsZ is located innermost, and how SmdA is located at the two septal membranes. Scale bars, $0.5 \mu \mathrm{m}$. 
Fig. 6. Membrane attachment and the NERD domain are important for SmdA function.

(A) HADA stained $S$. aureus NCTC8325-4 control cells not expressing any SmdA-variant

(IM307) and cells overexpressing SmdA $\Delta$ TMH (MK1911), SmdA $\Delta$ TMH_mut1 (IM377), _mut2 (IM378) and_mut3 (IM379). Scale bars, $2 \mu \mathrm{m}$. (B) The frequency of cells from panel

A with normal or abnormal HADA staining is plotted. The number of cells plotted were 259 the control, 82 for SmdA $\triangle \mathrm{TMH}, 101$ for_mut1, 113 for_mut2 and 122 for _mut3. The asterisks indicate significant difference form the control (Fisher's exact test, $\mathrm{P}<0.001$ ). ns indicates that there is not significant difference from the control. (C) Structure of SmdA, predicted by AlphaFold (52), where (C-I) shows the structure colored by a "per-residue confidence score" (pLDDT) with dark blue pLDDT $>90$, light blue $90>$ pLDDT $>70$, and yellow $70>$ pLDDT $>50$, $(\mathbf{C}$-II $)$ shows the structured domain magnified with the predicted NERD colored in green and residues that have been mutated in red. (C-III) A magnified inset of (II) with annotated residues. The positions of the mutated residues are indicated in red. (D) Growth assay on solid media of $S$. aureus NCTC8325-4 expressing SmdA $\triangle \mathrm{TMH}$, 1056 SmdA $\triangle \mathrm{TMH}$ _mut1,_mut2 and_mut3. 
1058 Figures and figure legends

1060 Table 1. Minimum inhibitory concentration (MIC, in $\mu \mathrm{g} / \mathrm{ml}$ ) of different antimicrobials

1061 when SmdA was depleted in S. aureus SH1000 and COL.

\begin{tabular}{|c|c|c|c|c|c|c|}
\hline \multirow[b]{2}{*}{ Antibiotics } & \multicolumn{3}{|c|}{ S. aureus SH1000 (MSSA) } & \multicolumn{3}{|c|}{ S. aureus COL (MRSA) } \\
\hline & $\mathrm{SmdA}^{\text {down }}$ & Control & $\begin{array}{l}\text { Fold } \\
\text { change }\end{array}$ & SmdA down & Control & $\begin{array}{l}\text { Fold } \\
\text { change }\end{array}$ \\
\hline Oxacillin & 0.12 & 0.24 & 2 & $64-128$ & 256 & $2-4$ \\
\hline Cefotaxime & 2 & 2 & 1 & 50 & 400 & 8 \\
\hline Cefoxitin & 1 & 2 & 2 & $47-94$ & 188 & $2-4$ \\
\hline Imipenem & 0.016 & 0.016 & 1 & 150 & $>300$ & $>2$ \\
\hline Vancomycin & 2.5 & 2.5 & 1 & 2.5 & 2.5 & 1 \\
\hline Tetracycline & 0.05 & $0.1-0.2$ & $2-4$ & $\geq 64$ & $\geq 64$ & 1 \\
\hline Ciprofloxacin & 0.32 & 0.32 & 1 & 0.32 & 0.32 & 1 \\
\hline Tunicamycin & 0.094 & 6 & 64 & 24 & $>96$ & $>4$ \\
\hline Targocil & 1 & 1 & 1 & 1 & 1 & 1 \\
\hline Congo Red & 256 & $>1024$ & $>4$ & $512-1024$ & $>1024$ & $\geq 2$ \\
\hline
\end{tabular}




\section{Legends to supplementary material}

Fig. S1. Multiple sequence alignment of SmdA from different staphylococcal species.

Protein sequences were aligned with Clustal Omega (78). The blue shaded residues are predicted to be extracellular, the transmembrane domain is shaded in grey, and the predicted NERD domain is shaded in yellow. S. aureus NCTC8325-4 is highlighted in bold, and residues that were mutated are marked in green. The accession numbers of the sequences are indicated, and the first five letter in the sequence tags indicate the genus or species corresponding the to the sequences (for example, Nosoc; Nococomiicoccus, Aliic; Aliicoccus, Salin; Salinicoccus, epidermidis, Mcase; Macrococcus caseolyticus, Ssciu; Staphylococcus sciuri, Sinte; Staphylococcus intermedius).

1076

1077

Fig. S2. Growth of SmdA knockdown strains in liquid cultures and verification of $s m d A$

silencing. (A) Growth of SmdA ${ }^{\text {down }}$ in S. aureus SH1000 (IM269) compared to the CRISRPicontrol strain with a non-targeting sgRNA (IM284). IPTG (300 $\mu \mathrm{g} / \mathrm{ml})$ was added to induce expression of the CRISPRi-system and $\mathrm{CFU} / \mathrm{ml}$ and $\mathrm{OD}_{600}$ measured every hour for five hours. (B) Verification of $s m d A$ silencing by PCR with RT-PCR. cDNA was synthesized from RNA isolated from induced and un-induced cultures of SH1000 SmdA ${ }^{\text {down }}$ (IM269) and the CRISPRi control strains (IM284; non-targeting sgRNA and IM165; empty plasmid without sgRNA). Primers targeting either $s m d A$ or the housekeeping gene $p t a$.

Fig. S3. Transmission electron microscopy (TEM) of different $S$. aureus strains with 
(A) NCTC8325-4 (IM311 and IM307), (B) HG001 (IM312 and IM313) and (C) COL (IM294 and IM295). Th e sizes of the scale bars are indicated in the images.

Fig. S4. Scanning electron microscopy (SEM) of cells depleted of SmdA. SEM micrographs of SmdA ${ }^{\text {down }}$ and control cells in S. aureus (A) HG001 (IM312 and IM313) and (B) COL (IM294 and IM295). All scale bars, $1 \mu \mathrm{m}$.

1094

1095

Fig. S5. Overexpression of SmdA. (A) Induced expression of an ectopic copy of $s m d A$ in the plasmid pLOW in S. aureus NCTC8325-4 (MK1866). Cells were labelled with the cell wall marker fluorescent vancomycin (VanFL). Scale bar, $2 \mu \mathrm{m}$. (B) Autolysis of S. aureus SmdA overexpression strain (MK1866) compared to plasmid control strain (MK1465) monitored in presence of $0.5 \%$ Triton X-100. Results presented as $\%$ of initial $\mathrm{OD}_{600}$. Error bars represent standard error calculated from four technical replicates.

1101

Fig. S6. Analysis of teichoic acids. (A-B) Lipoteichoic acid (LTA) detection by 1103 immunoblotting with $\alpha$-LTA antibody was performed with (A) cell extract samples from SmdA $^{\text {down }}$ and CRISPRi control cells from S. aureus SH1000 (IM269 and IM284), NCTC8325-4 (IM311 and IM307), HG001 (IM312 and IM313) and COL (IM294 and IM295), and (B) cell extract (CE)- and supernatant (SN) samples from SmdA ${ }^{\text {down }}$ and CRISPRi control cells from S. aureus SH1000 and NCTC8325-4 (IM269, IM284, IM311 and IM307, respectively). In (A), the mean intensities in the bands (background subtracted) were determined using Fiji (71). The mean intensities of the LTA bands in the smdA depletions relative to their controls are plotted. All control strains express a non-targeting sgRNA. (C-D) SmdA does not have major impact on the synthesis of wall teichoic acids. (C) TEM micrographs of S. aureus NCTC8325-4 control strain (IM307) compared to SmdA and TarO 
1114 high-density layer in the septum, which is missing in the TarO depletion strain (white arrow).

(D) Fourier transform infrared spectroscopy (FTIR) of S. aureus HG001 control strain (IM313)

1116 and knockdown strain of SmdA and TarO (IM312 and IM357, respectively). The

1117 polysaccharide region of the spectrum is shown, and the indicated peaks represents $\alpha$ - and $\beta$ glycosidic bonds.

1119

Fig. S7. Bacterial two-hybrid analysis demonstrating self-interaction between SmdA proteins.

Blue bacterial spots indicate positive interactions and white spots indicate no interaction.

Table S1. Proteins pulled down with SmdA-GFP.

1124

Table S2. Strains used in this study.

Table S3. Primers used in this study. 
bioRxiv preprint doi: https://doi.org/10.1101/2021.11.23.469651; this version posted February 12 2022. The copyright holder for this

preprint (which was not certified by peer review) is the author/funder, who has granted bioRxiv a license to display the preprint in perpetuity. It is made available under aCC-BY-NC-ND 4.0 International license.

Fig. 1

A

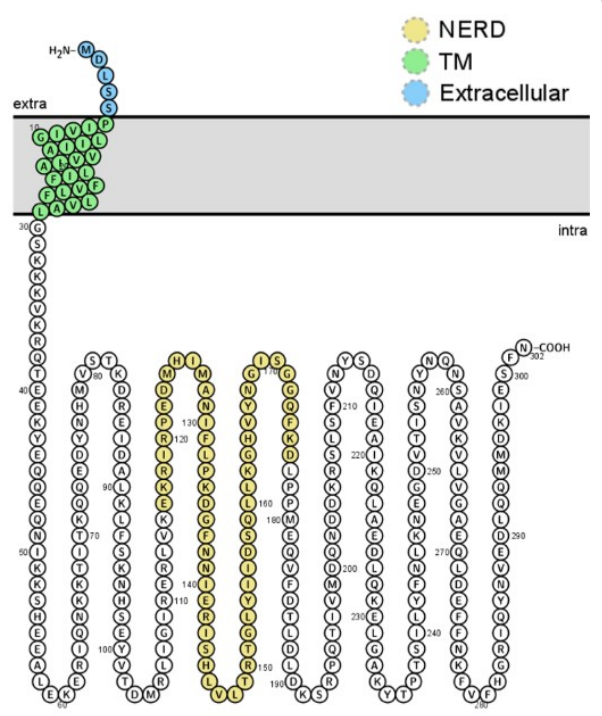

B

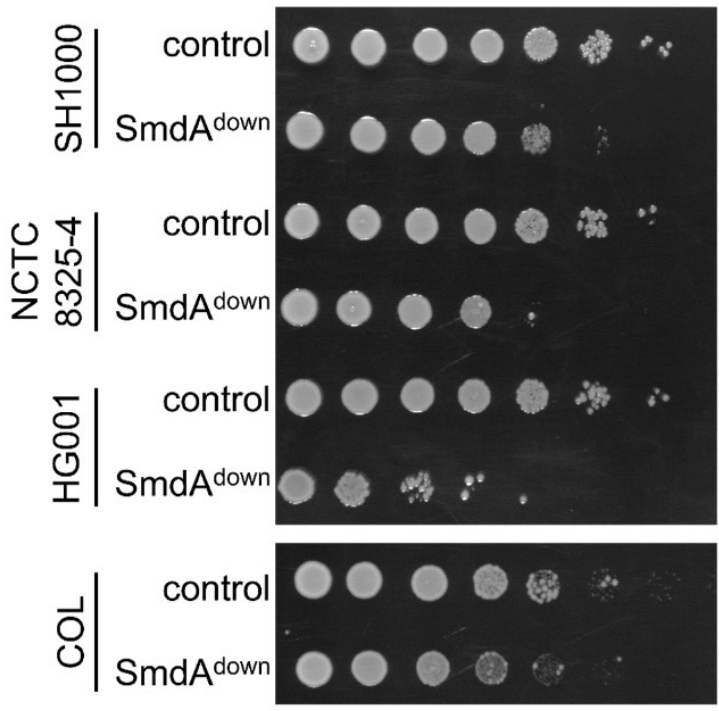

C

Phase contrast

VanFL

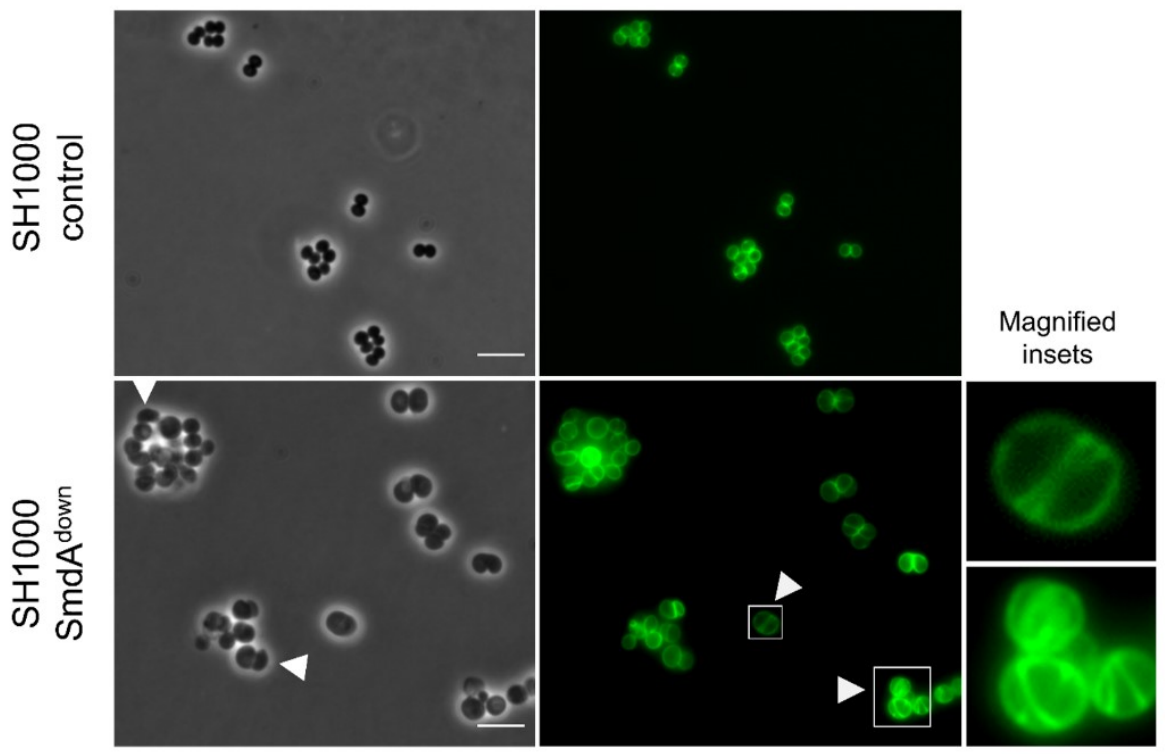

D Multiple

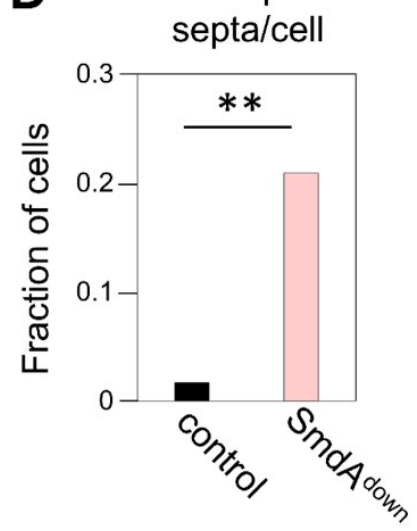

E

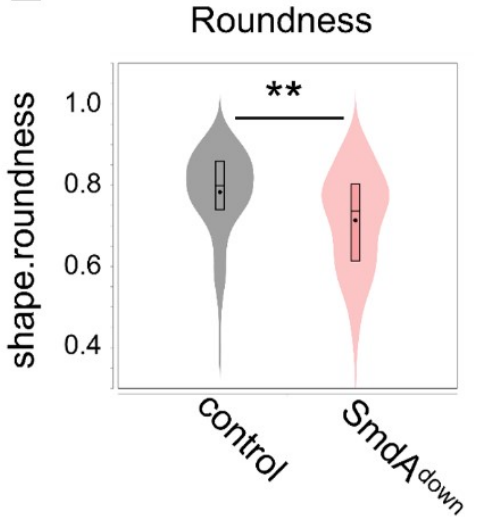

$\mathbf{F}$

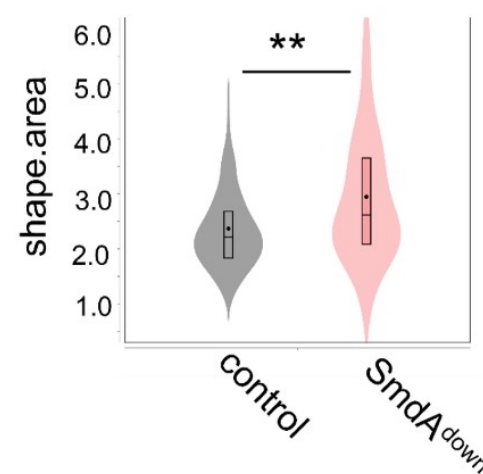


bioRxiv preprint doi: https://doi org/10.1101/2021.1123.469651; this version posted February 12, 2022. The copyright holder for this

preprint (which was not certified by peer review) is the author/funder, who has granted bioRxiv a license to display the preprint in perpetuity. It is made available under aCC-BY-NC-ND 4.0 International license.

Fig. 2

A

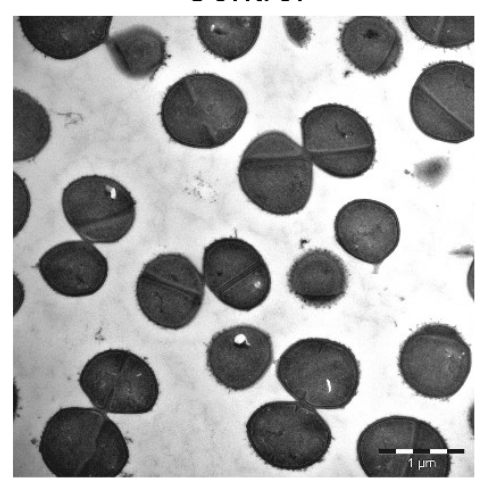

SmdA down

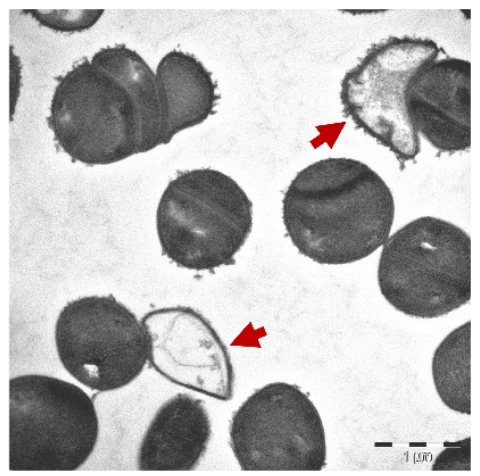

SmdA down
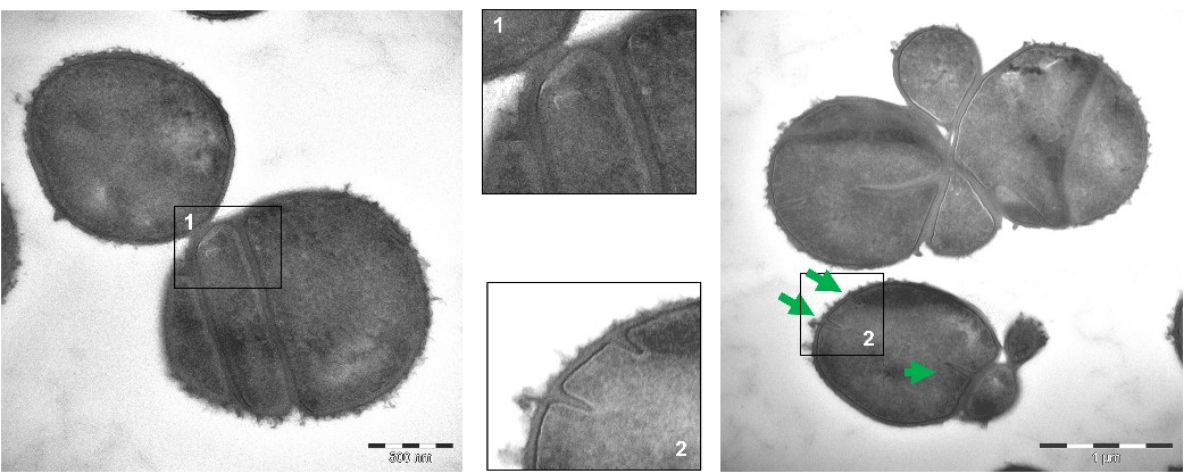

B

Control

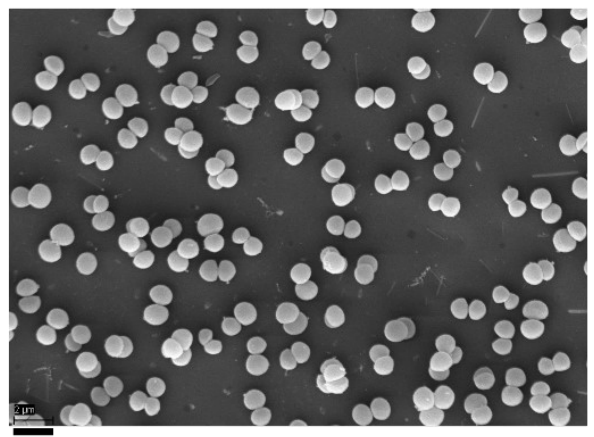

$2 \mu \mathrm{m}$

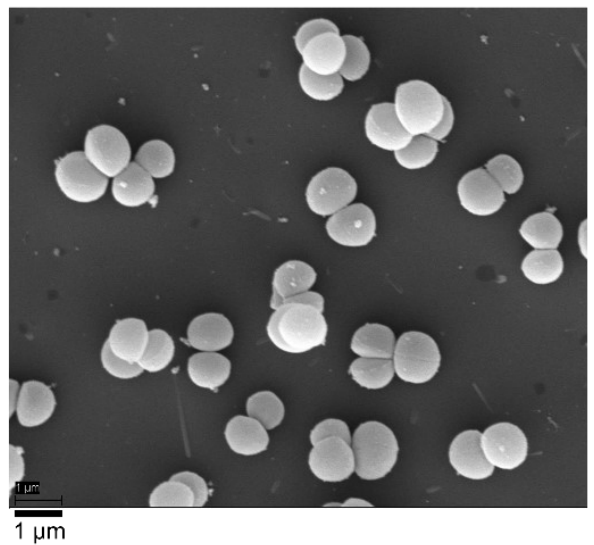

SmdAdown

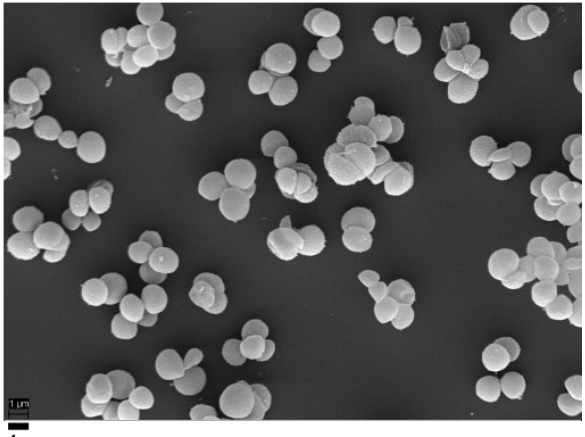

$\overline{1} \mu \mathrm{m}$

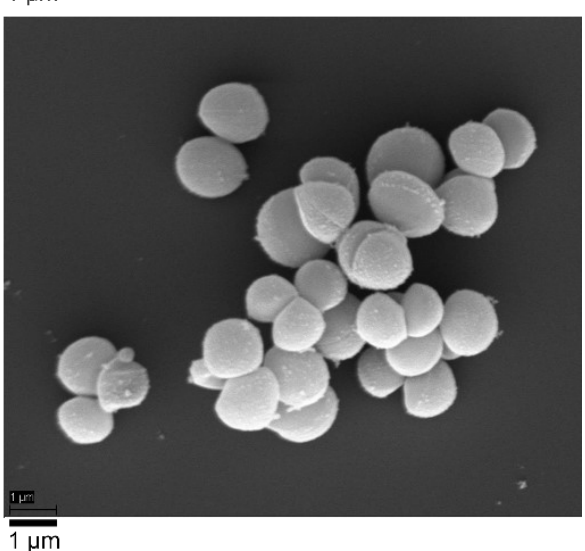


bioRxiv preprint doi: https://doi.org/10.1101/2021.1123.469651; this version posted February 12, 2022. The copyright holder for this

Fig. 3

A
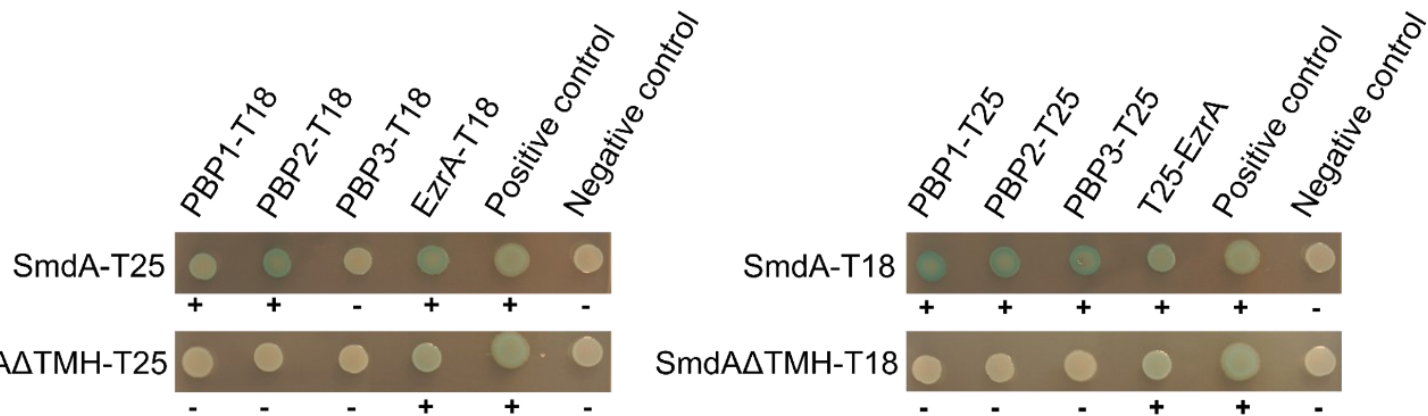

B

Phase contrast

HADA

E
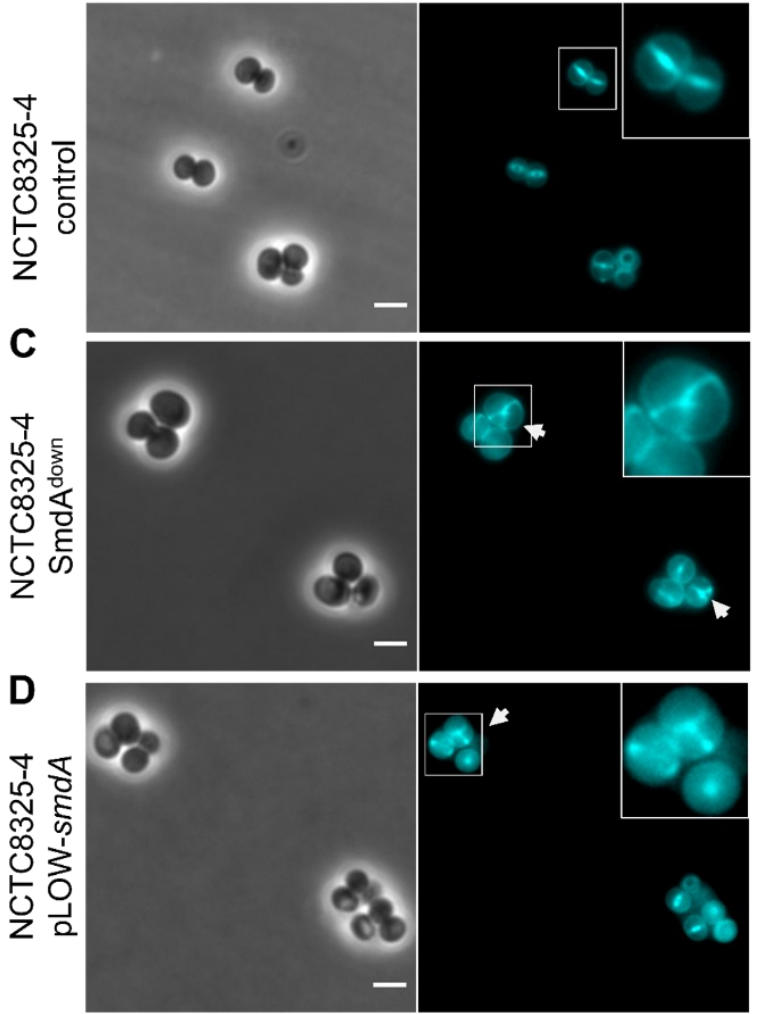

F

HADA

EzrA-GFP
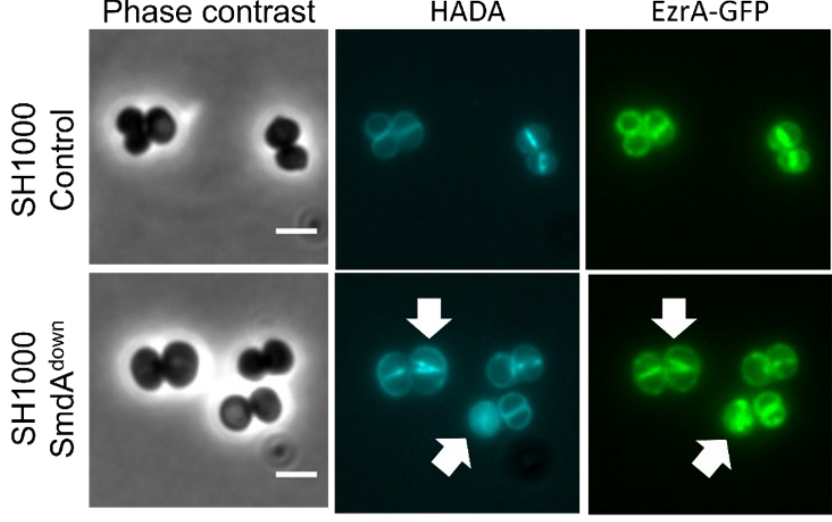

G

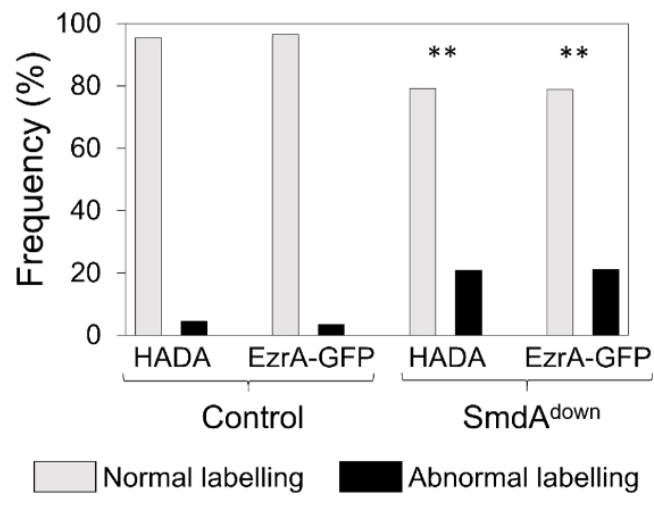


bioRxiv preprint doi: https://doi.org/10.1101/2021.11.23.469651; this version posted February 12 2022. The copyright holder for this

Fig. 4
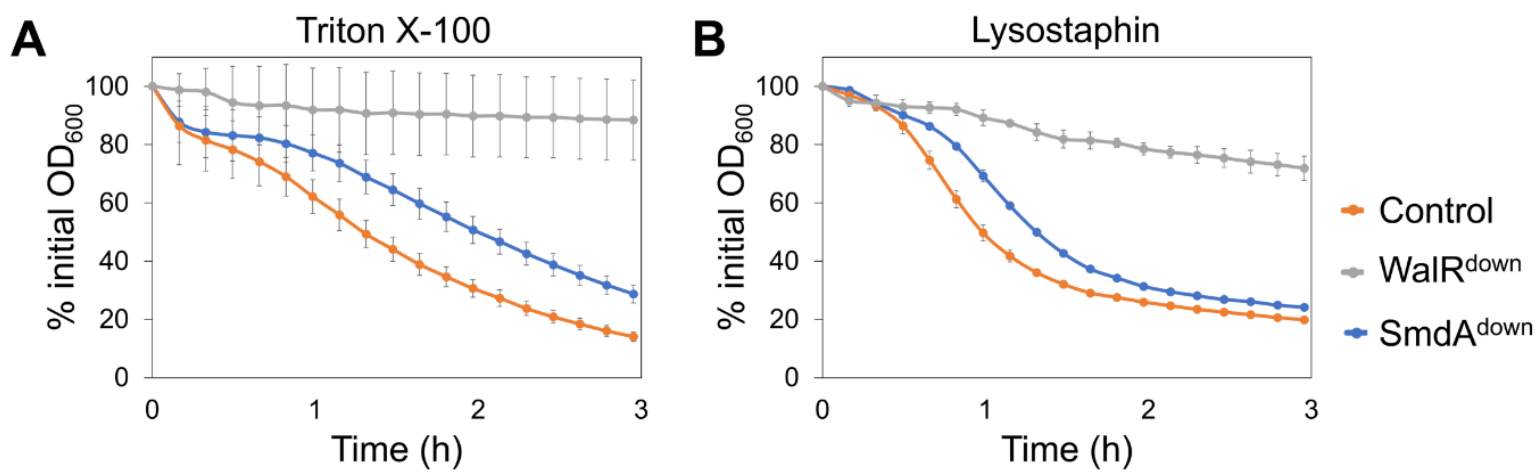

$1138 \quad$ Fig. 5

A
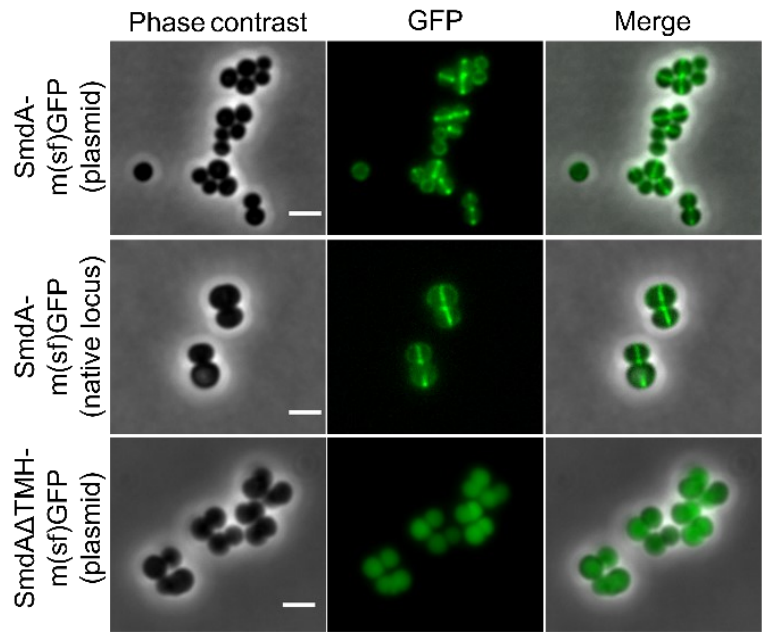

C

SmdA- FtsZmYFP mKate2 Merge
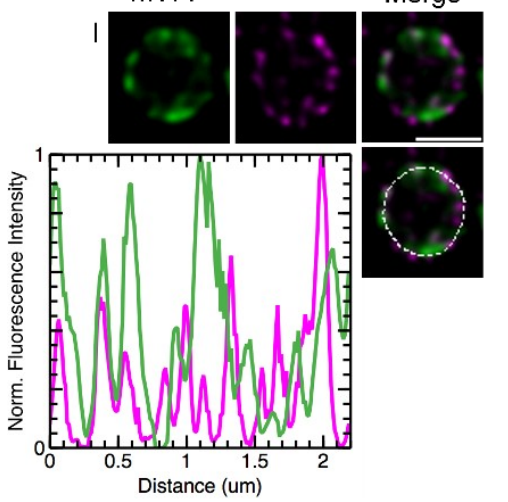

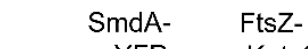

mYFP mKate2
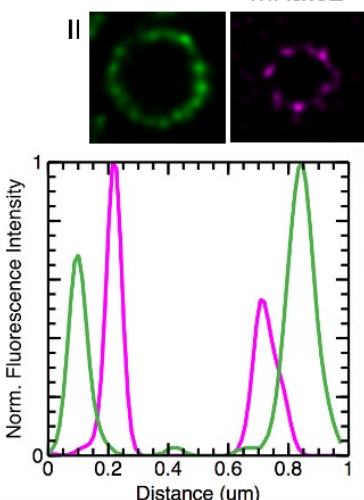

B

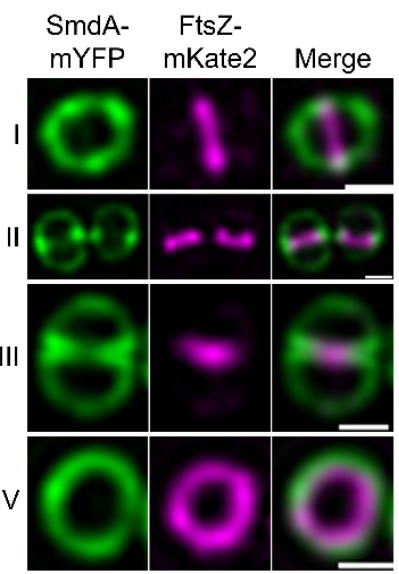

Merge
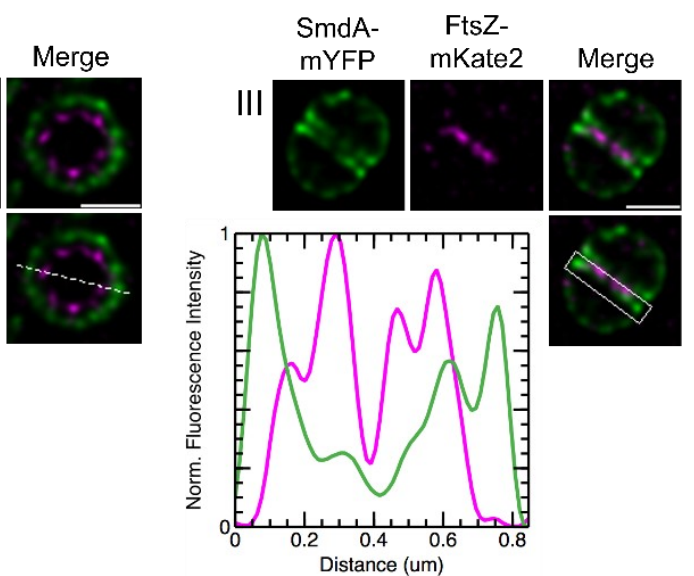
bioRxiv preprint doi: https://doi org/10.1101/2021.1123.469651: this version posted February 12 2022. The copyright holder for this preprint (which was not certified by peer review) is the author/funder, who has granted bioRxiv a license to display the preprint in perpetuity. It is made available under aCC-BY-NC-ND 4.0 International license.

Fig. 6

A
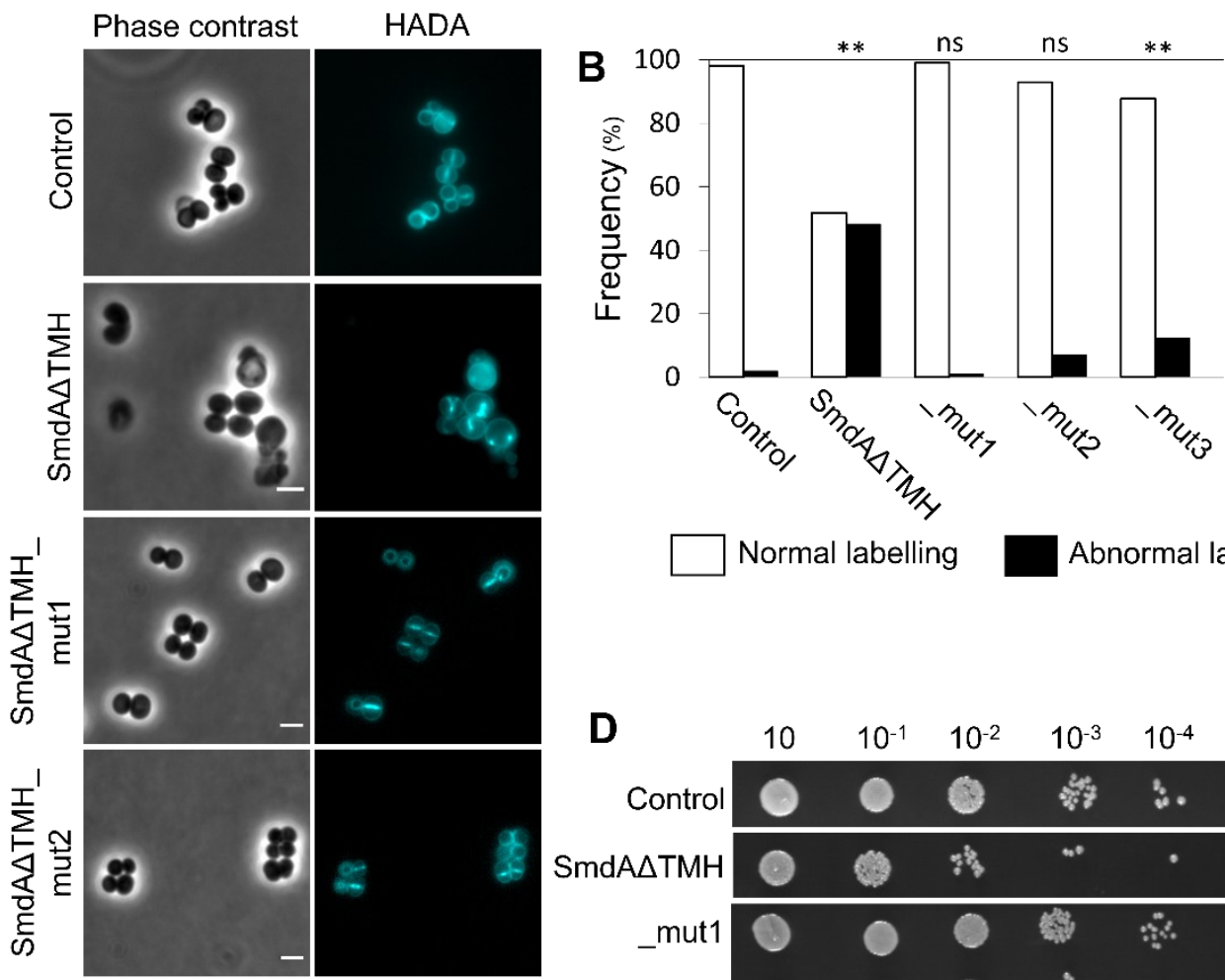

D
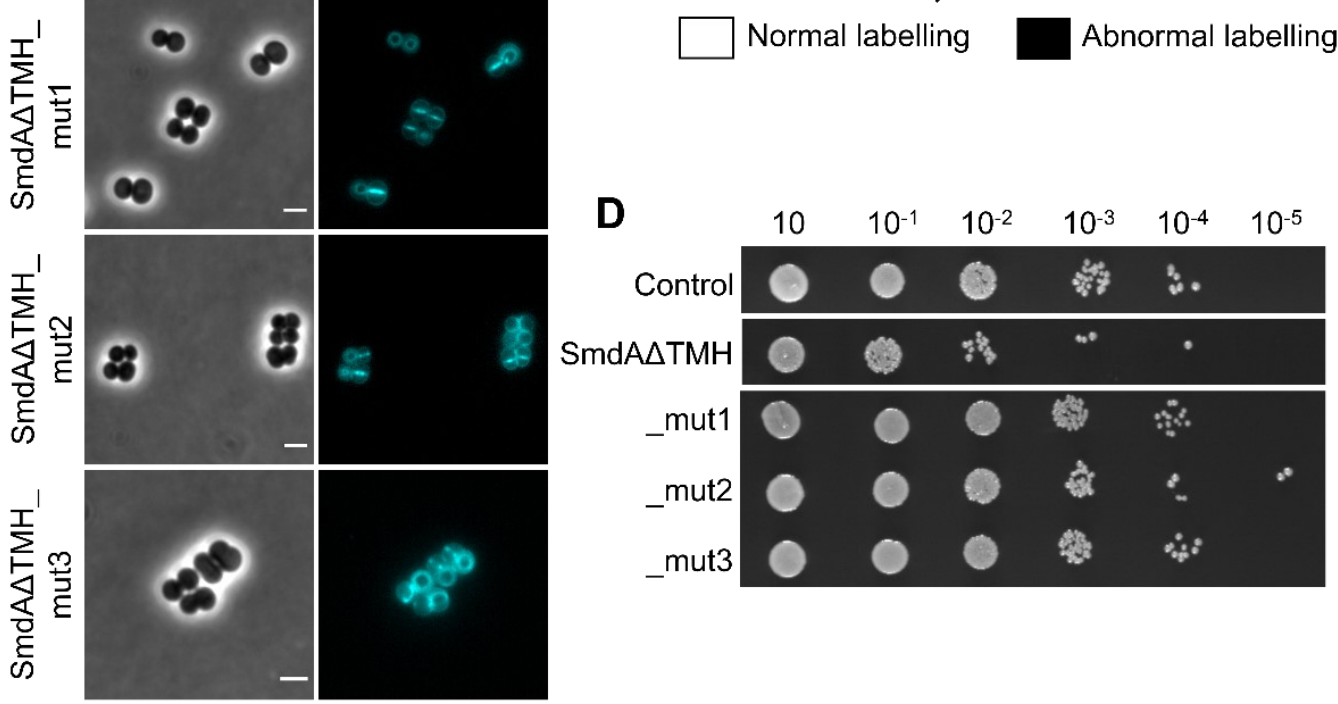

\begin{tabular}{|c|c|c|c|c|c|c|}
\hline & 10 & $10^{-1}$ & $10^{-2}$ & $10^{-3}$ & $10^{-4}$ & $10^{-5}$ \\
\hline Control & 0 & 0 & 0 & 䒹 & s. & \\
\hline $\mathrm{dA} \triangle \mathrm{TMH}$ & O & $\Leftrightarrow$ & 73 & $m$ & - & \\
\hline _mut1 & 0 & 0 & 0 & 4 & "צ: & \\
\hline _mut2 & 0 & 0 & 0 & कै & $\therefore$ & $\bullet$ \\
\hline _mut3 & 0 & 0 & 0 & 4 & $\dot{x}$ & \\
\hline
\end{tabular}

C
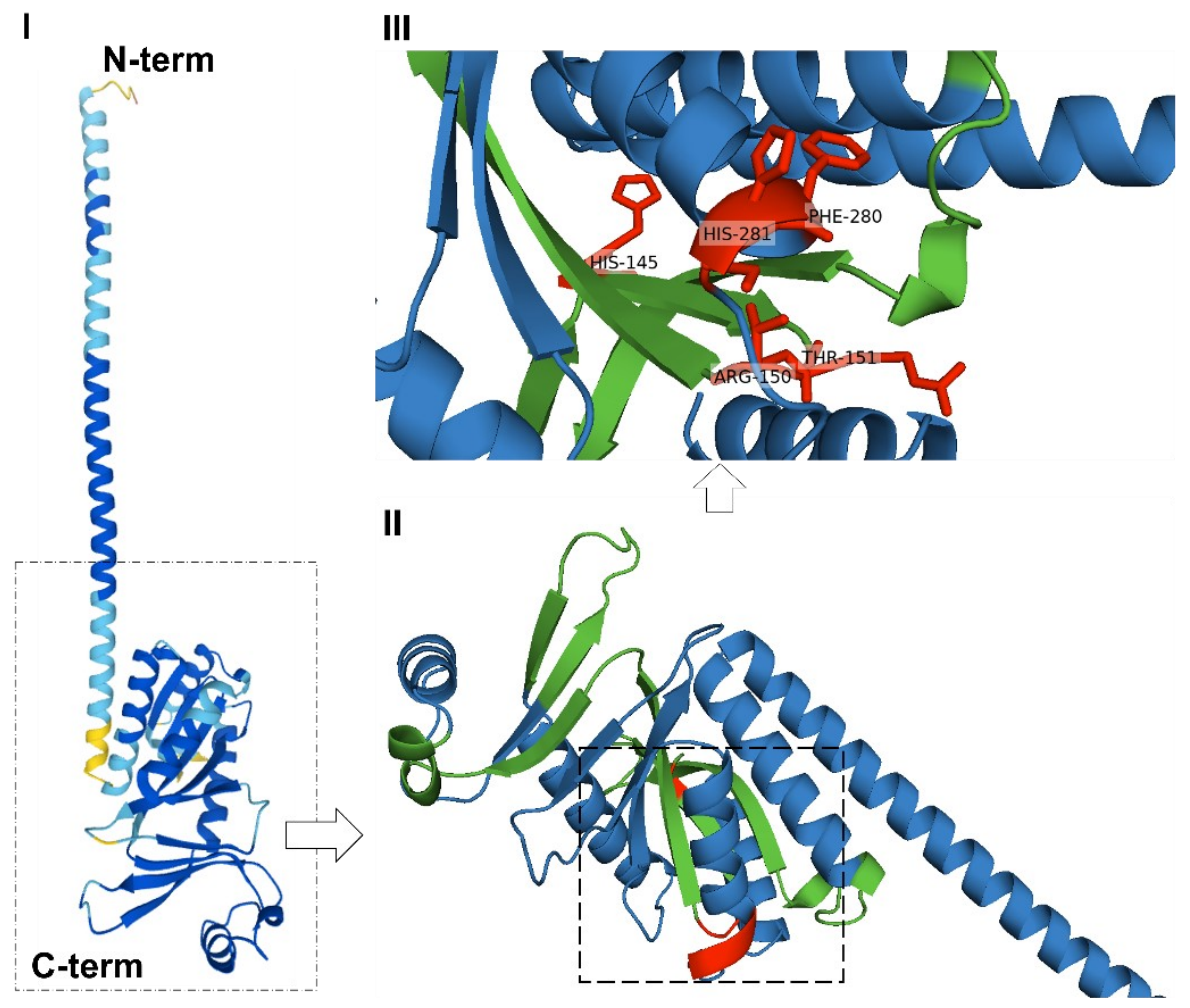